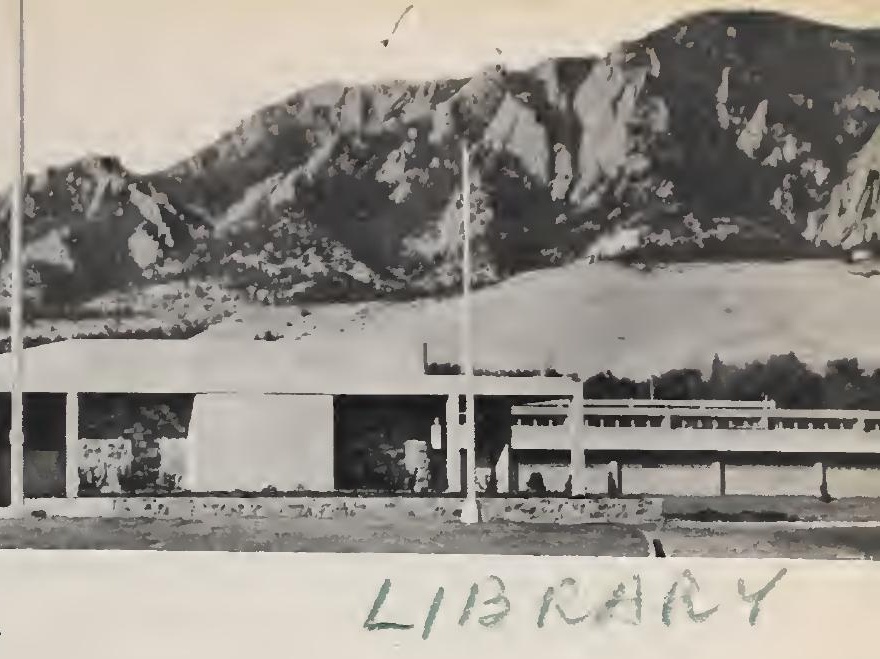

6010

PRELIMINARY MEASUREMENTS OF

PHASE STABILITY OVER LOW-LEVEL TROPOSPHERIC PATHS

by

M. C. Thompson, Jr. and H. B. Janes

NBS

U. S. DEPARTMENT OF COMMERCE NATIONAL BUREAU OF STANDARDS

BOULDER LABORATORIES

Boulder, Colorado 


\section{THE NATIONAL BUREAU OF STANDARDS}

\section{Functions and Activities}

'The functions of the National Burcalu of Standards are set forth in the Act of Congress, March 3, 1901, as amended by Congress in Public Law 619, 1950. These inclucle the development and maintenance of the national stanclards of measurement and the provision of means and methods for making measurements consistent with these standards: the determination of physical constants and properties of materials; the development of methods and instruments for testing materials, devices, and structures; advisory services to Government Agencies on scientific and technical problems; invention and development of devices to serve special needs of the Government; and the development of standard practices, codes and specifications. The work includes basic and applied research, development, engineering, instrumentation, testing, evaluation, calibration services, and various consultation and information services. A major portion of the Bureau's work is performed for other Government Agencies, particularly the Department of Defense and the Atomic Energy Commission. The scope of activities is suggested by the listing of divisions and sections on the inside back cover.

\section{Reports and Publications}

The results of the Bureau's work take the form of either actual equipment and devices or published papers and reports. Reports are issued to the sponsoring agency of a particular project or program. Published papers appear either in the Bureau's own series of publications or in the journals of professional and scientific societies. The Bureau itself publishes three monthly periodicals, available from the Government Printing Office: The Journal of Research, which presents complete papers reporting technical investigations; the Technical News Bulletin, which presents summary and preliminary reports on work in progress; and Basic Radio Propagation Predictions, which provides clata for determining the best frequencies to use for radio communications throughout the world. There are also five series of nonperiodical publications: The Applied Math. ematics Series, Circulars, Handbooks, Building Materials and Structures Reports, and Miscellaneous Publications. 


\section{NATIONAL BUREAU OF STANDARDS REPORT}

NBS PROJECT

$8300-11-8805$
NBS REPORT

6010

PRELIMINARY MEASUREMENTS OF

PHASE STABILITY OVER LOW-LEVEL TROPOSPHERIC PATHS

by

M. C. Thompson, Jr. and H. B. Janes

The research contained

in this report was sponsored in part by the Air Force Ballistic Missile Division - AF04 (647) - 134 .

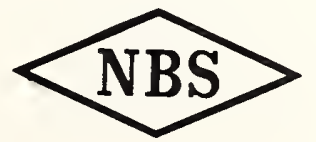

U. S. DEPARTMENT OF COMMERCE NATIONAL BUREAU OF STANDARDS BOULDER LABORATORIES

Boulder, Colorado 
NATIONAL BUREAU OF STAN Approved for public release by the ments intended for use within is subjected to odditionol evoluc mission is obtoined in listing 25 , D. C. Such permission is $n$ been specificolly prepored if the ogress occounting docuis formolly published it on, reprinting, reproduct outhorized unless perF Stondards, Woshington or which the Report hos for its own use. 
TABLE OF CONTENTS

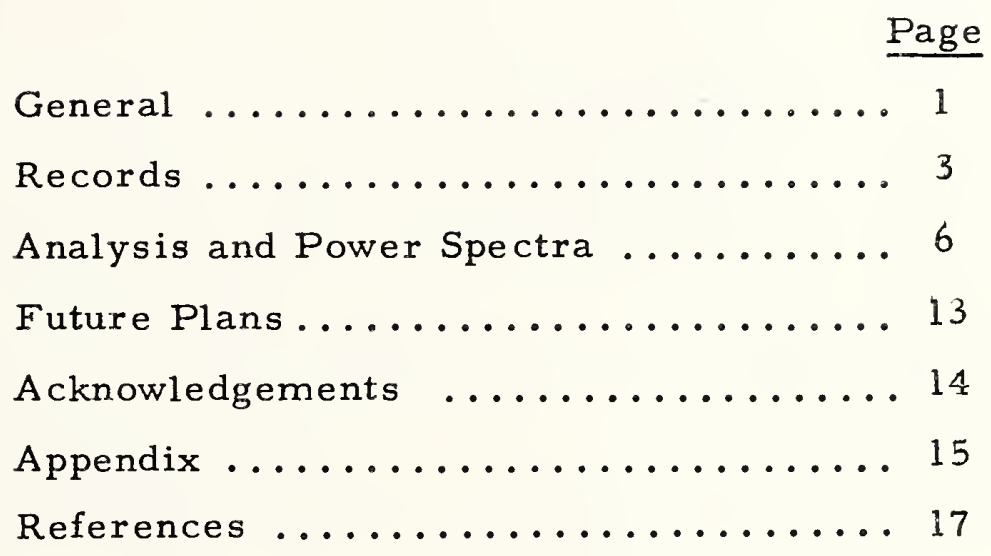





\section{LIS'T OF ILLUSTRATIONS}

1. Plan of path

2. Profile of path

3. Photo of Green Mt. Mesa terminal

4. Photo of Table Mesa terminal

5. Photo from Green Mt. Mesa to Table Mesa

6. Photo from Table Mesa to Green Mt. Mesa

7. Pressure, wind speed, and wind direction, each terminal for 40 hours

8. Relative humidity, temperature, $\mathrm{N}_{\mathrm{s}}$ and phase, each terminal for 4.0 hours

9. Scaled-down phase and $\mathrm{N}_{\mathrm{s}}$ record to show 40 hours continuous

10. Sample of Varian chart, frontal passage

11. Sample of Varian chart, fair weather

12. Samples of Sanborn chart

13. Sanborn channel frequency response

14. Composite phase spectrum

15. Phase spectrum from Varian chart

16. Phase spectrum from Sanborn chart

17. Composite spectra for horizontal and vertical polarization

18. Composite spectra for horizontal and vertical polarization

19. Composite frequency variation spectrum 
PRELIMINARY MEASUREMENTS OF

PHASE STABILITY OVER LOW-LEVEL TROPOSPHERIC PATHS

by

M. C. Thompson, Jr, and H. B. Janes

\section{GENERAL}

The first run for observing phase variations over a low-level path was made from $1100^{\mathrm{h}}, 9-15-58$, to $1625^{\mathrm{h}}, 9-17-58$. The path (Figs. 1-6) was from Green Mt. (about 1/2 mile west of the Boulder Laboratories) to Table Mesa, (about 10 miles north of the Boulder Laboratories).

As shown in Fig. 2, each antenna was located at the edge of a steep slope avoiding ground reflections in the immediate vicinity. The path passed over two valleys, each running east-west and separated from each other by a relatively flat-topped mesa. This latter would appear to constitute the major ground-reflection area and included in the region of the radio path a small lake (Roberts Lake). The path length as deterrnined from the best maps available is 9.4 miles. The data were obtained mostly using horizontal polarization, but with three periods using vertical polarization. The instrumentation was an elaboration of that described earlier. The measuring frequency was approximately $9400 \mathrm{MC}$ and the antennas were $18^{\prime \prime}$ diameter parabolic dished mounted from two to five feet above local ground surface. Four types of phase records were obtained:

1. Low pass (0-1 cps) with sensitivity of $2 \frac{1}{2}$ wave-lengths $\left(900^{\circ}\right)$ full-scale.

2. Low pass $(0-1 \mathrm{cps})$ with sensitivity of $100^{\circ}$ full scale. 
3. Band-pass (0.03-1 cps) with sensitivity from $2.5^{0}$ to $12.5^{0}$ full-scale.

4. Band-pass (0.03-10 cps) with sensitivity from $1.6^{0}$ to $8^{0}$ full-scale.

Record No. 1 was made on a Varian G-11 chart recorder operated at $0.1 \mathrm{inch} / \mathrm{min}$.

Records Nos. 2 and 3 were made on Esterline-Angus charts at $311 / \mathrm{min}$, and $121 \% \mathrm{~min}$. respectively.

Record No. 4 was made on a Sanborn recorder at $25 \mathrm{~mm} / \mathrm{sec}$.

Supplementary data (Figs. 7 and 8 ) consisted of surface measurements of temperature, pressure, relative humidity, wind speed and direction at each terminal. During the period of this run the general meteorological conditions are summarized as follows:

A cold front moved across the path (roughly in a direction normal to the path) during the period 1000 to 1200 , September 15. The winds, temperature drop, and increase in relative humidity are indicated by Figs. 7 and 8 . From about 1300 until 1830 the sky was overcast in all directions and a light rain fell steadily over all or part of the path to about. 17 inch total. During the night patches of ground fog developed. As daylight came on September 16, from the tops of the mesas (the path terminals) fog could be seen for many miles to the NE. $E$, and $S E$ lying in the low areas of the terrain. Following sunrise at about 0540 , these pockets of fog were dispelled progressively until by 1000 the entire area was clear with excellent visibility and partially cloudy sky. Pikes Peak was clearly visible from the Table Mesa site from the onset of daylight (about 90 miles distance). The remainder of the run was conducted in completely clear weather conditions. 


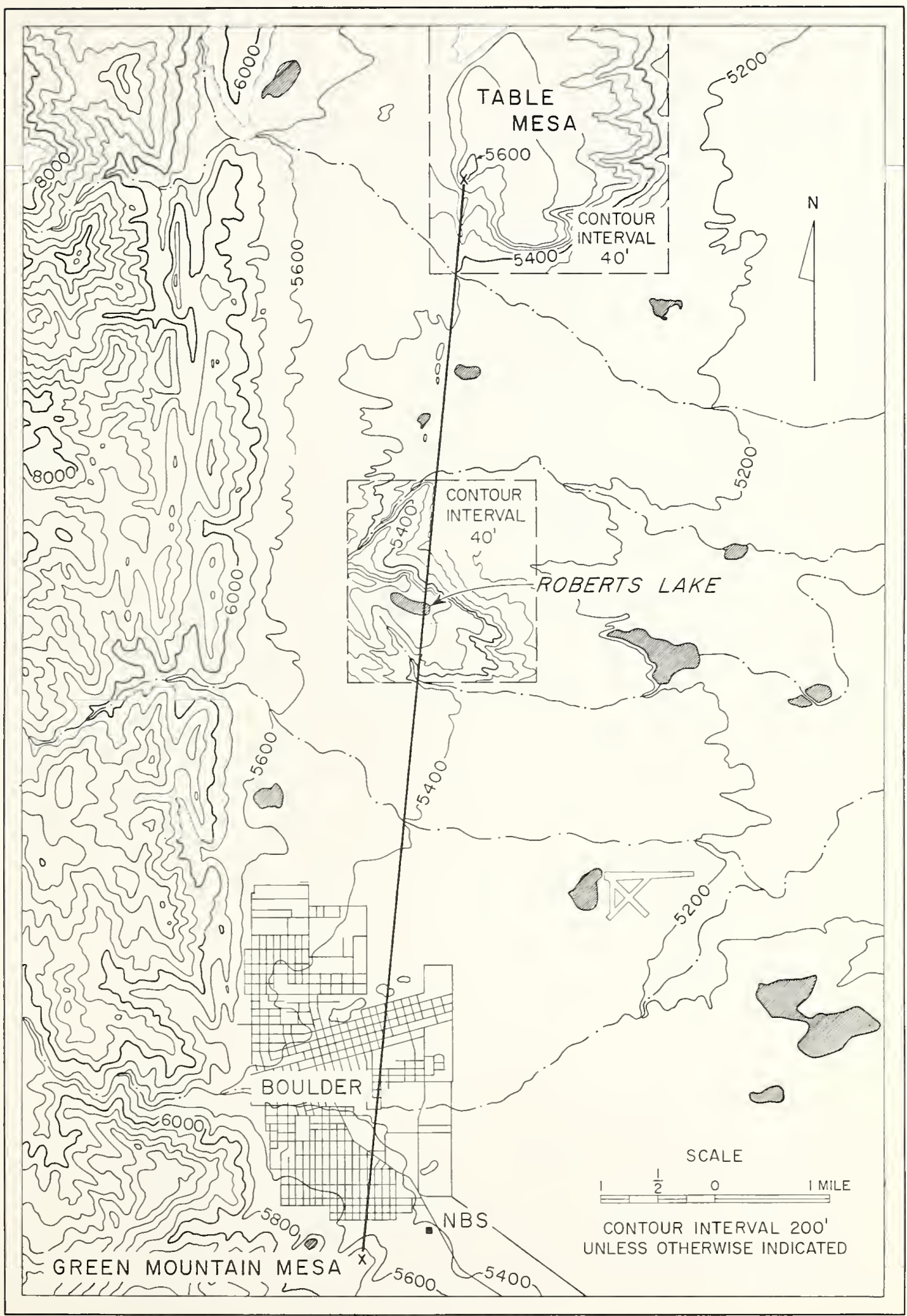




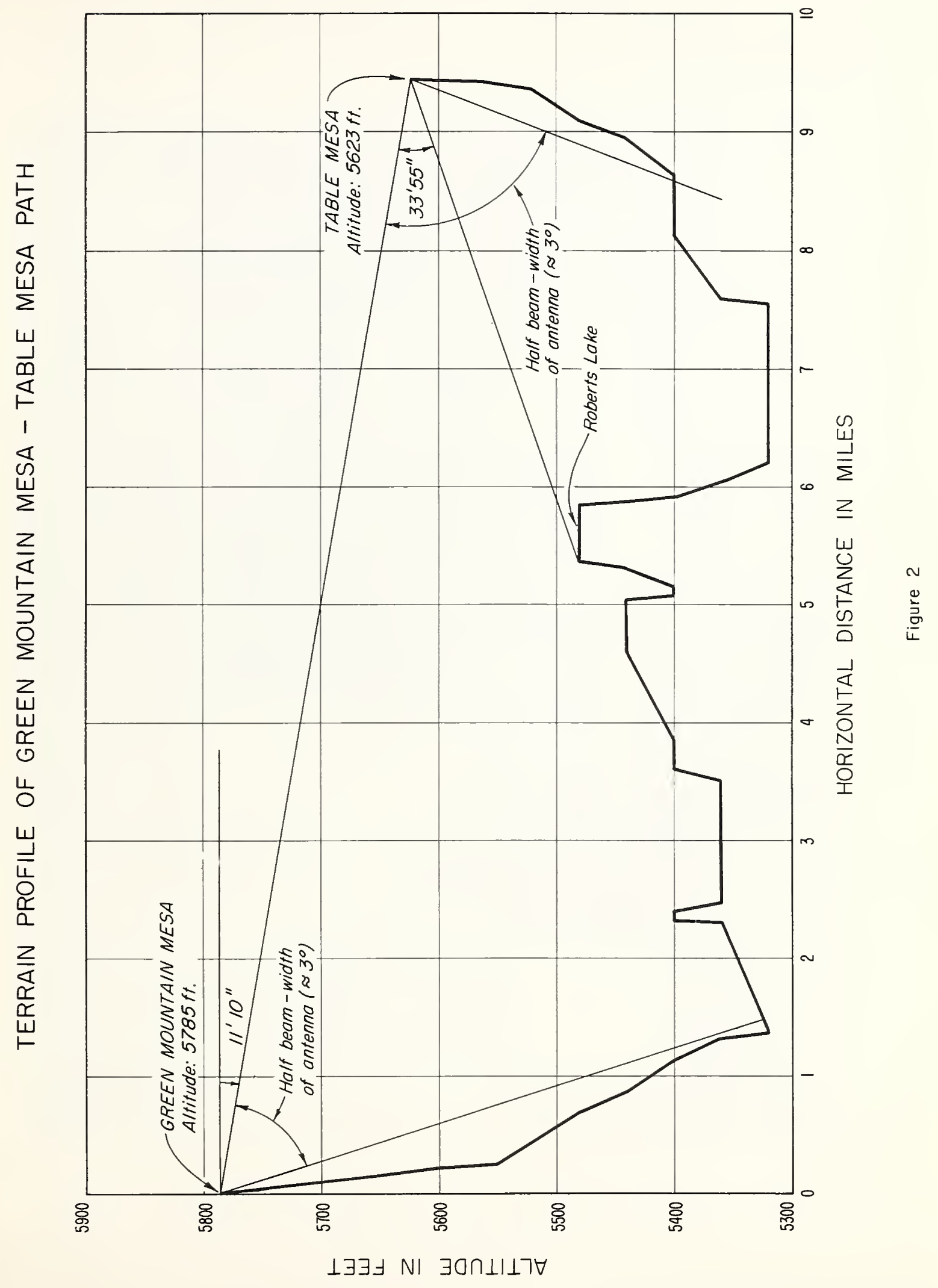





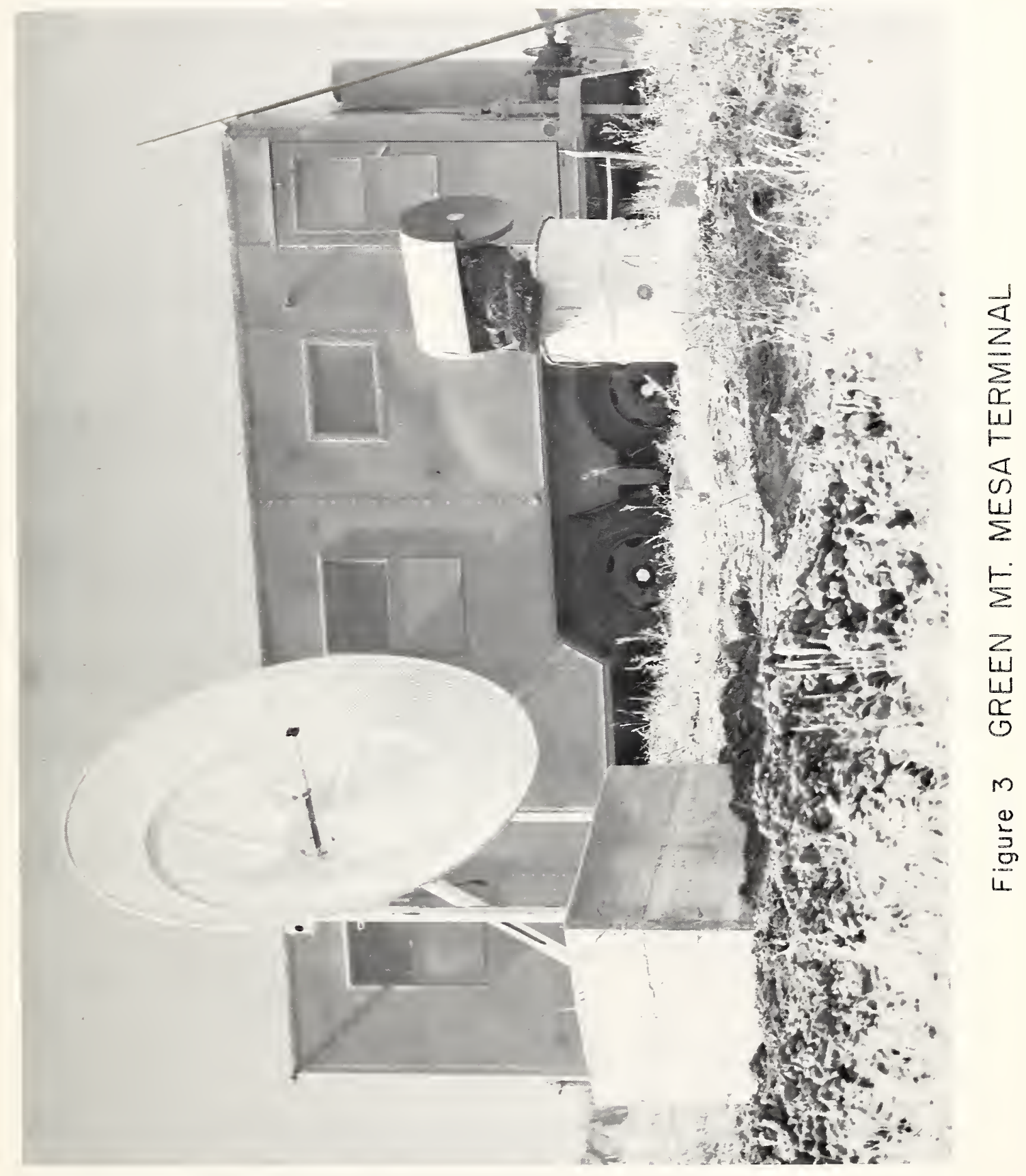




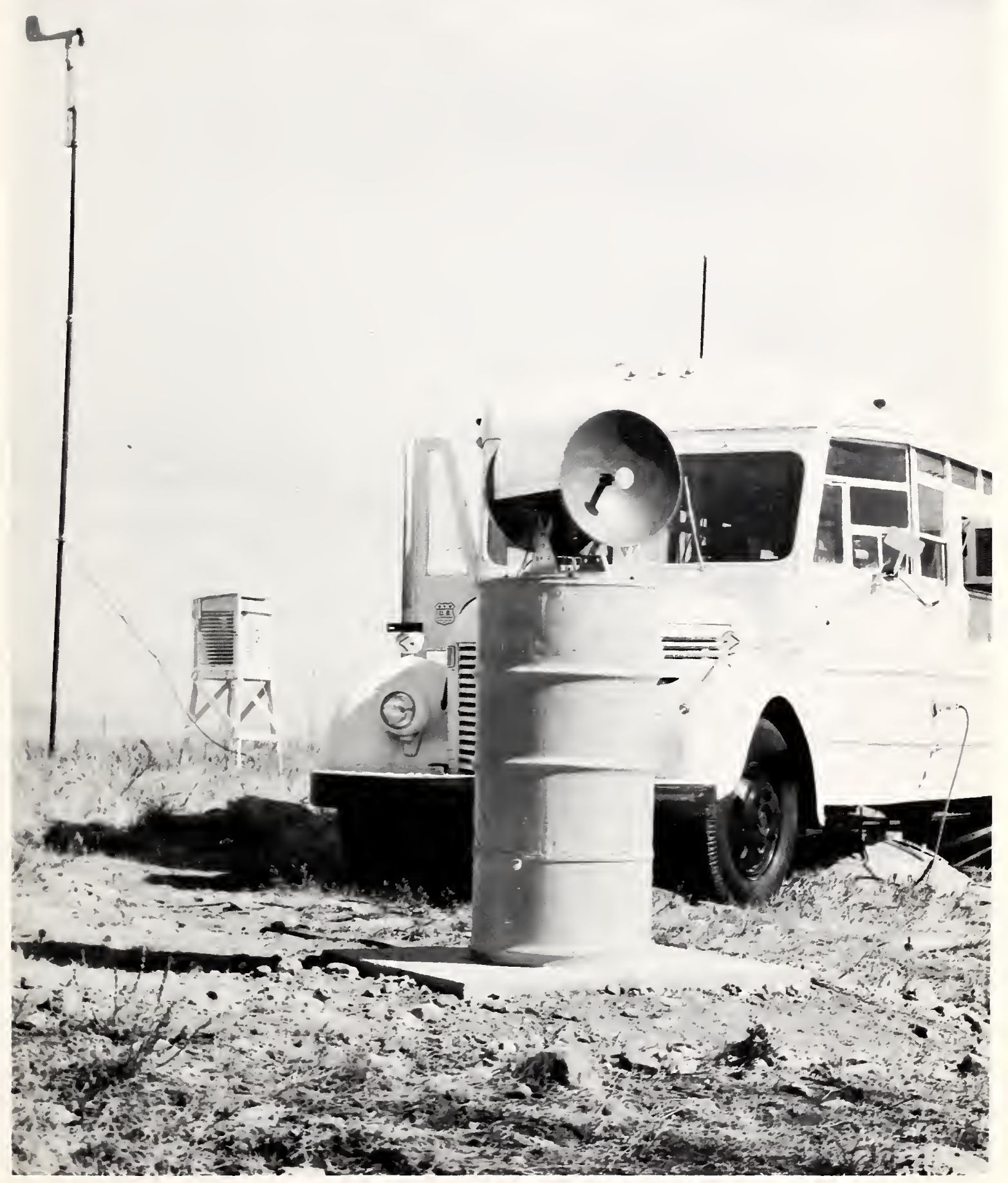

Figure 4 TABLE MESA TERMINAL 



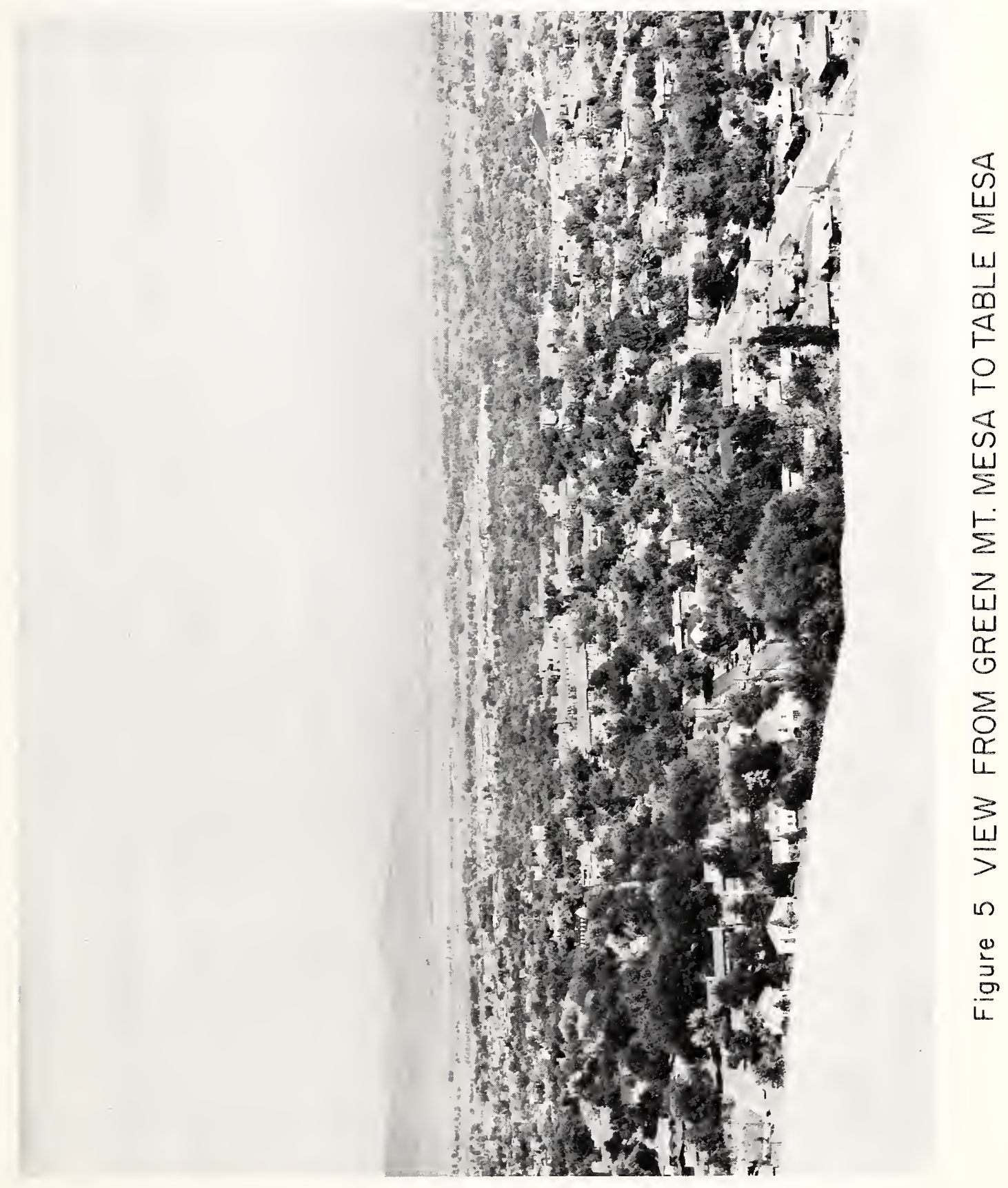




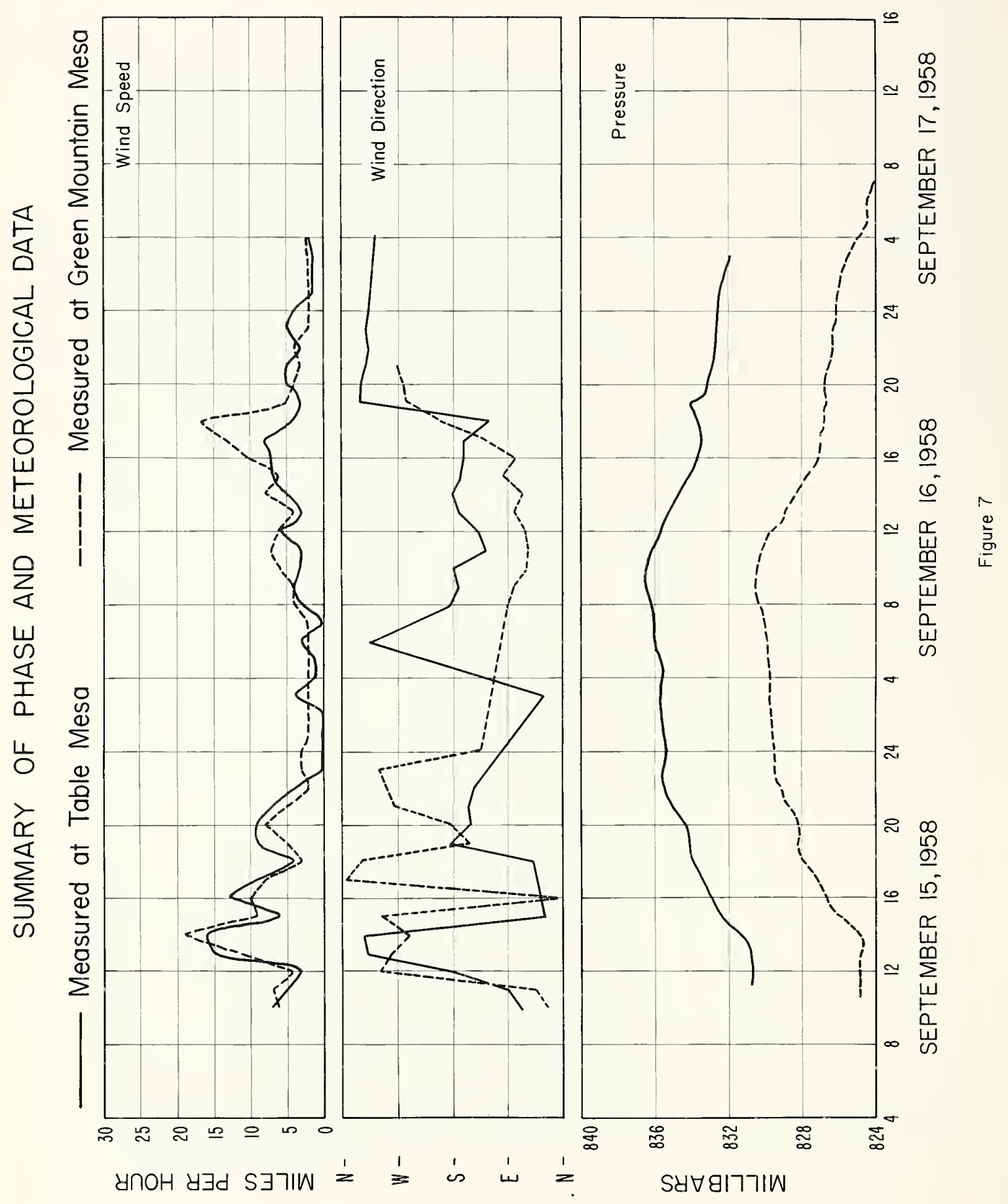



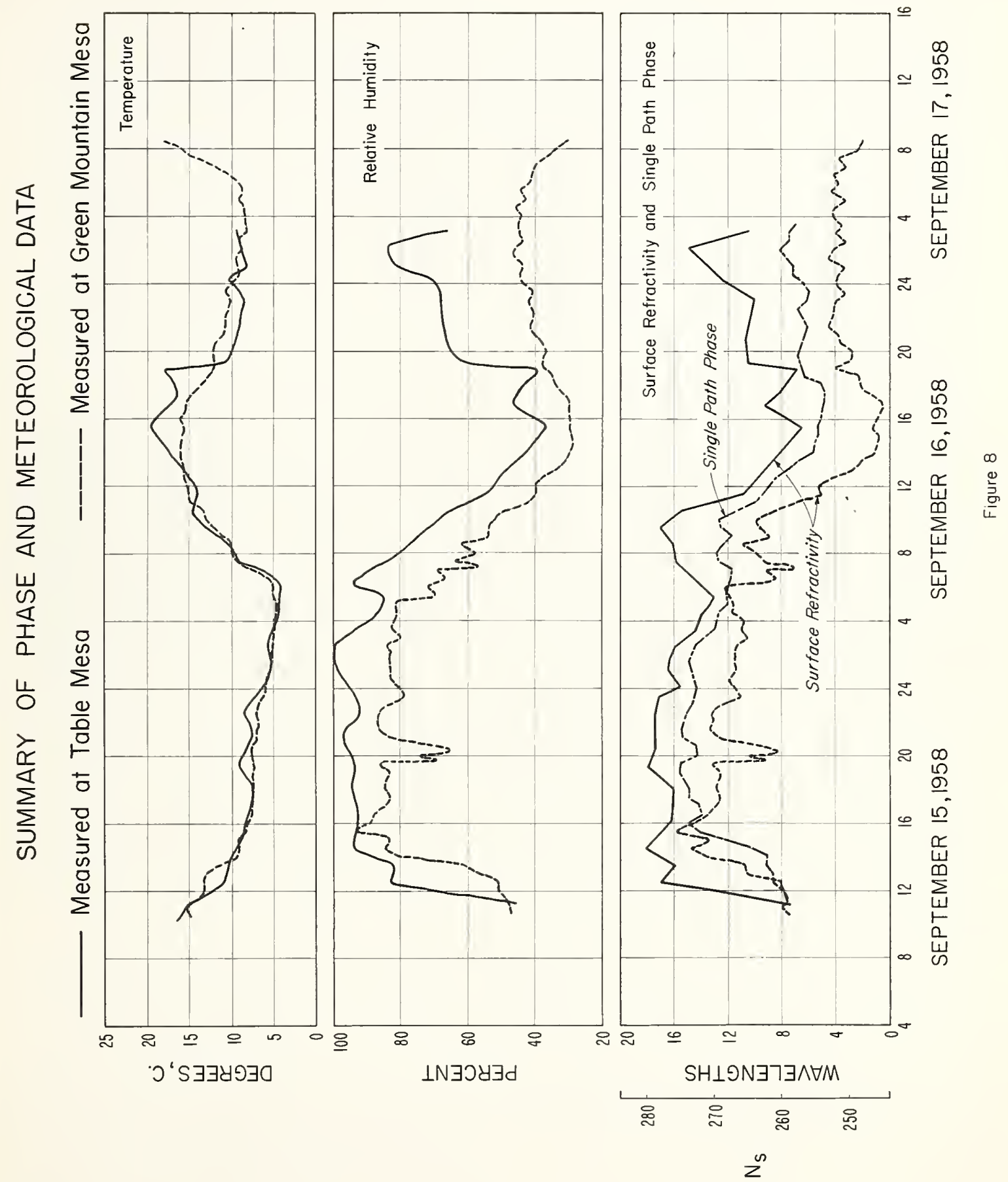



\section{RE.CORDS}

The band-pass E.sterline-Angus and Sanborn record samples obtained are summarized in Tables I and II. A continuous record of phase from $1110^{\mathrm{h}}$, 9-15-58, through $0340^{\mathrm{h}}, 9-17-58$ (40.5 hours) was obtained from the Varian chart which has proved valuable in evaluating interruptions in the other charts.

The general nature of the phase variations is indicated by the scaled-down plot of Fig. 9 and by the samples shown in Figs. 10, 11, and 12 .

Fig. 9 illustrates the comparative behavior between the phase variation over the entire path and the surface refractive index (about 5 feet above ground level) as measured at each path terminal. (For this run the index was calculated from psychrometric and barometric measurements). For the entire period of the run a correlation of 0.915 was obtained between the phase and the average of the end-point indices. This correlation seems clearly to be a function of the period over which it is computed. This is the greatest deg1ee of correlation noted to date between these parameters. This may be due, in part, to the frontal passage and particularly to the fact that the motion of the front was approximately normal to the radio path so that essentially all parts of the path experienced the change in air mass at about the same time.

Figs, 10 and 11 , representing the same time interval for the two days, show the different behavior exhibited during the frontal passage and the clear weather. Similarly, the two samples of Fig. 12 indicate the differences in the rapid variations observed during the stormy and the quiet period. The quantitative differences are indicated in the spectra in the following section. 
TABLE I

Total number of band-pass Esterline-Angus samples: 31

Full-scale

\begin{tabular}{|c|c|c|c|c|}
\hline Run No. & Date & Time Ser & ity, Degrees & Polarization \\
\hline 1 & $9-15-58$ & $1110-1117$ & 12.5 & Horiz. \\
\hline 2 & $9-15-58$ & $1129-1144$ & 5 & Horiz. \\
\hline 3 & $9-15-58$ & $1243-1246$ & 12.5 & Horiz. \\
\hline 4 & $9-15-58$ & $1546-1553$ & 5 & Horiz. \\
\hline 5 & $9-15-58$ & $1814-1830$ & 5 & Horiz. \\
\hline 6 & $3-15-58$ & $2042-2057$ & 5 & Horiz. \\
\hline 7 & $9-16-58$ & $0039-0054$ & 5 & Horiz. \\
\hline \multirow[t]{2}{*}{8} & $9-16-58$ & $0154-0200$ & 5 & Horiz. \\
\hline & $9-16-58$ & $0201-0209$ & 2.5 & Horiz. \\
\hline 9 & $9-16-58$ & $0424-0430$ & 5 & Horiz. \\
\hline 10 & $9-16-58$ & $0432-0435$ & 5 & Horiz. \\
\hline 11 & $9-16-58$ & $0520-0535$ & 5 & Horiz. \\
\hline 12 & $9-16-58$ & $0747-0803$ & 5 & Horiz. \\
\hline 13 & $9-16-58$ & $0946-094930$ & 5 & Horiz. \\
\hline 14 & $9-16-58$ & $0956-1004$ & 5 & Horiz. \\
\hline 15 & $9-16-58$ & $1150-115030$ & 5 & Horiz. \\
\hline \multirow[t]{2}{*}{16} & $9-16-58$ & $1202-1204:$ & & \\
\hline & & $1204-1209$ & 12.5 & Horiz. \\
\hline \multirow[t]{2}{*}{17} & $9-16-58$ & $1314-1316:$ & & \\
\hline & & $1316-1320$ & 12.5 & Horiz. \\
\hline 18 & $9-16-58$ & $1352-1358$ & 12.5 & Horiz. \\
\hline 19 & $9-16-58$ & $1416-1419$ & 12.5 & Horiz. \\
\hline 20 & $9-16-58$ & $1436-1440$ & 12.5 & Horiz. \\
\hline 21 & $9-16-58$ & $1524-1528$ & 12.5 & Horiz. \\
\hline \multirow[t]{2}{*}{22} & $9-16-58$ & $160115-1615$ & & \\
\hline & & $1615-161850$ & 5 & Horiz. \\
\hline 23 & $9-16-58$ & $1823-182930$ & 5 & Horiz. \\
\hline 24 & $9-16-58$ & $1843-185130$ & 5 & Horiz. \\
\hline 25 & $9-16-58$ & $1854-1908$ & 5 & Horiz. \\
\hline 26 & $9-16-58$ & $2111-2123$ & 5 & Horiz. \\
\hline 27 & $9-16-58$ & $2315-2343$ & 12.5 & Horiz. \\
\hline 28 & $9-17-58$ & $1005-100730$ & 12.5 & Horiz. \\
\hline 29 & $9-17-58$ & $1352-1410$ & 12.5 & Vert. \\
\hline 30 & $9-17-58$ & $1520-1549$ & 12.5 & Horiz. \\
\hline 31 & $9-17-58$ & $1602-1625$ & 12.5 & Vert. \\
\hline
\end{tabular}


TABLE: II

Total number of Sanborn Samples: 27

\begin{tabular}{|c|c|c|c|c|}
\hline Run No. & Date & Time & $\begin{array}{c}\text { Full-Scale } \\
\text { Sensitivity, Degrees } \\
\end{array}$ & Polarization \\
\hline 1 & $9-15-58$ & $1110-111030$ & 8 & Horiz. \\
\hline 2 & $9-15-58$ & $1130-1135$ & 3.2 & Horiz. \\
\hline 3 & $9-15-58$ & $1243-1247$ & 8 & Horiz. \\
\hline 4 & $9-15-58$ & $1551-1556$ & 3.2 & Horiz. \\
\hline 5 & $9-15-58$ & $1814-1819$ & 3.2 & Horiz. \\
\hline 6 & $9-15-58$ & $2039-2042$ & 3.2 & Horiz. \\
\hline 7 & $9-16-58$ & $0039-0044$ & 3.2 & Horiz. \\
\hline 8 & $9-16-58$ & $0154-0200$ & 3.2 & Horiz. \\
\hline 9 & $9-16-58$ & $0201-0209$ & 1.6 & Horiz. \\
\hline 10 & $9-16-58$ & $0432-0436$ & 3.2 & Horiz. \\
\hline 11 & $9-15-58$ & $0520-0530$ & 3.2 & Horiz. \\
\hline 12 & $9-16-58$ & $0747-0752$ & 3.2 & Horiz. \\
\hline 13 & $9-16-58$ & $0946-094930$ & 3.2 & Horiz. \\
\hline 14 & $9-16-58$ & $0956-1021$ & 3.2 & Horiz. \\
\hline 15 & $9-16-58$ & $1202-1208$ & 3.2 & Horiz. \\
\hline 16 & $9-16-58$ & $1352-1358$ & 8 & Horiz. \\
\hline 17 & $9-16-58$ & $1523-1528$ & 3.2 & Horiz. \\
\hline 18 & $9-16-58$ & $1601-1606$ & 3.2 & Horiz. \\
\hline 19 & $9-16-58$ & $1823-1828$ & 3.2 & Horiz. \\
\hline 20 & $9-16-58$ & $2111-2116$ & 3.2 & Horiz. \\
\hline 21 & $9-16-58$ & $2320-2325$ & 8 & Horiz. \\
\hline 22 & $9-17-58$ & $0825-0828$ & 8 & Horiz. \\
\hline 23 & $9-17-58$ & $1005-1008$ & 8 & Horiz. \\
\hline 24 & $9-17-58$ & $1352-1357$ & 8 & Vert. \\
\hline \multirow[t]{2}{*}{25} & $9-17-58$ & $1520-1524:$ & & \\
\hline & & $1524-1529$ & 8 & Horiz. \\
\hline 26 & $9-17-58$ & $1544-1549$ & 8 & Horiz. \\
\hline \multirow[t]{2}{*}{27} & $9-17-58$ & 160230 to & & \\
\hline & & $\sim 161500$ & 8 & Vert. \\
\hline
\end{tabular}




\section{ANALYSIS AND POWER SPECTRA}

One of the principal objectives of the experiment was to gather information on the power spectrum of time variations in the phase of a microwave signal propagated over a line-of-sight path。 In general, the range of frequencies for which the power spectral density can be estimated from a given record is determined by the length of the continuous recording obtained, the slope of the spectrum being estimated, and the frequency response characteristic of the recording system. In order to cover as much of the spectrum as possible, four recording systems were used to measure the phase variations.

The output of one was recorded on a Varian chart moving at the rate of 0.1 inch per minute. A full-scale sweep of the pen represented a change of 1800 degrees in the difference between the phase of the signals received at the two path terminals (almost) simultaneously. The "single-path phase" data discussed here was obtained by simply dividing this "two-way phase" by two. The frequency response characteristic of this recording circuit is essentially flat up to about 1 cycle per second. However, since the primary purpose of this record was to measure gross changes in phase, the dynamic range and chart speed used necessarily precluded the study of spectral frequencies above about 1 cycle per minute. Figs. 10 and 11 show retracings of the Varian record. The wide range of values recorded without loss of continuity was made possible by an automatic scale-shifting arrangement which prevented the trace from going off scale.

\footnotetext{
The method of estimating the power spectrum used here is that given by Blackman and Tukey 2/. Briefly, it consists of computing the Fourier cosine transform of the autocovariance function of the time series and applying appropriate weighting functions to the result.
} 


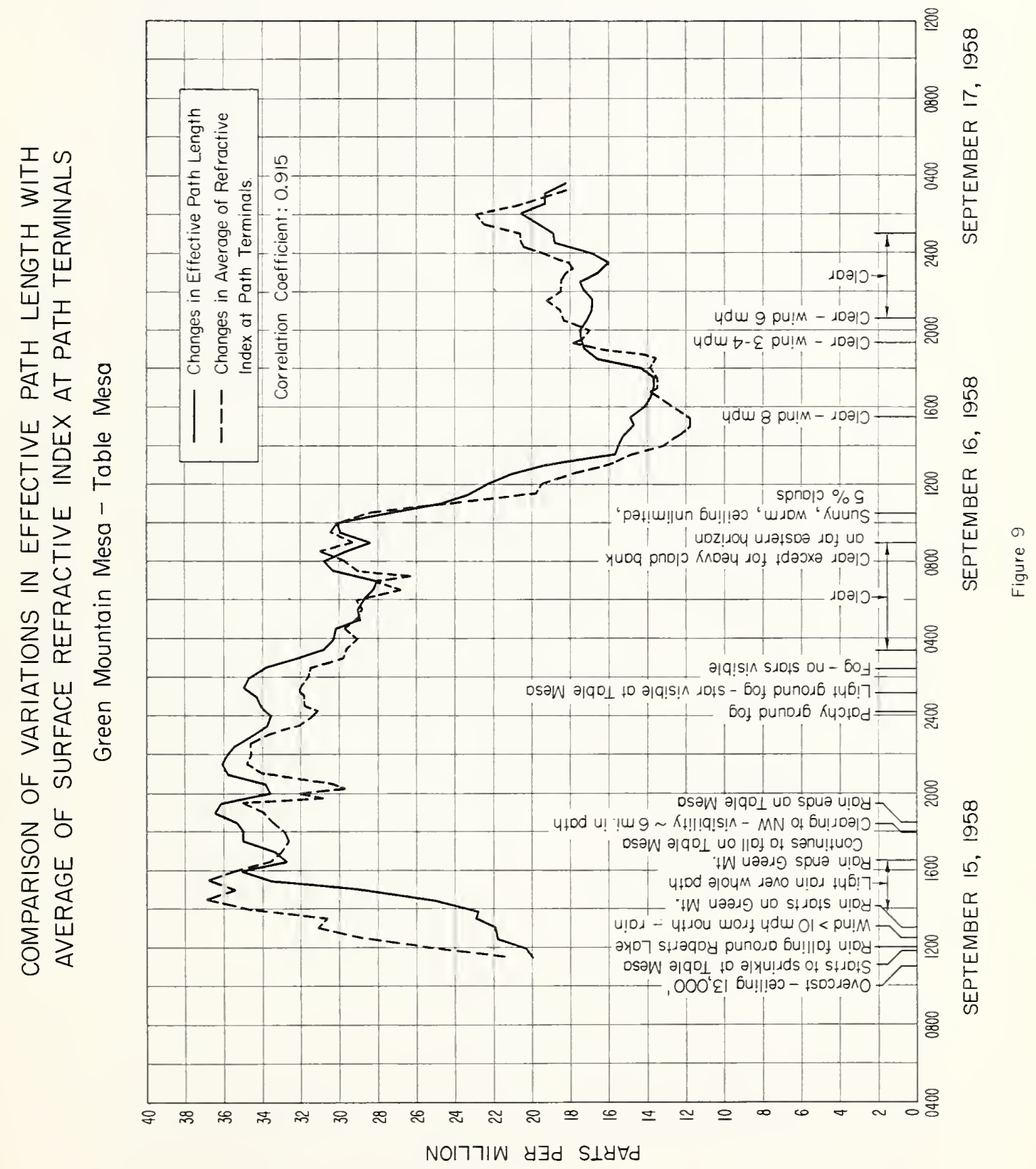





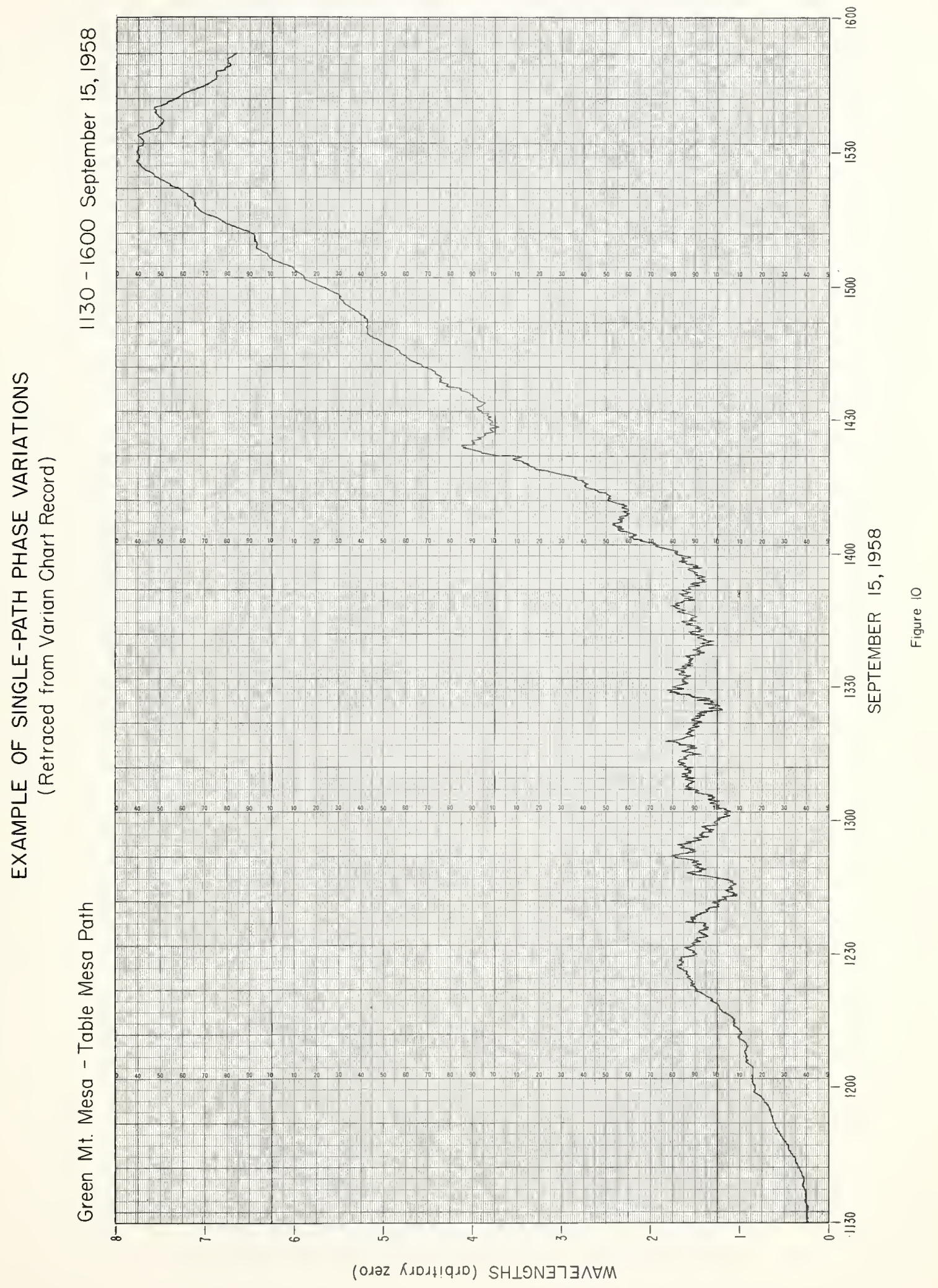





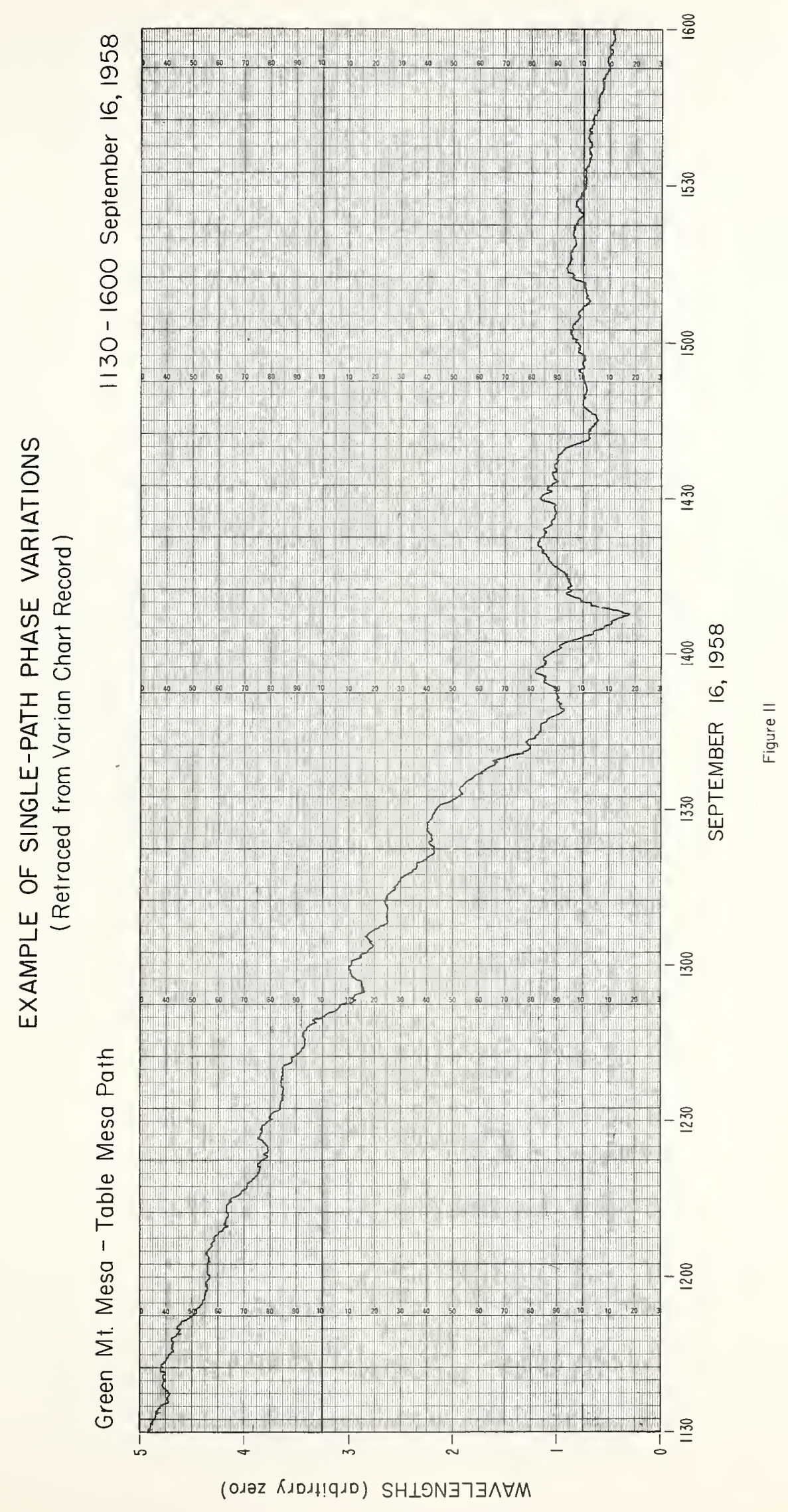


. 

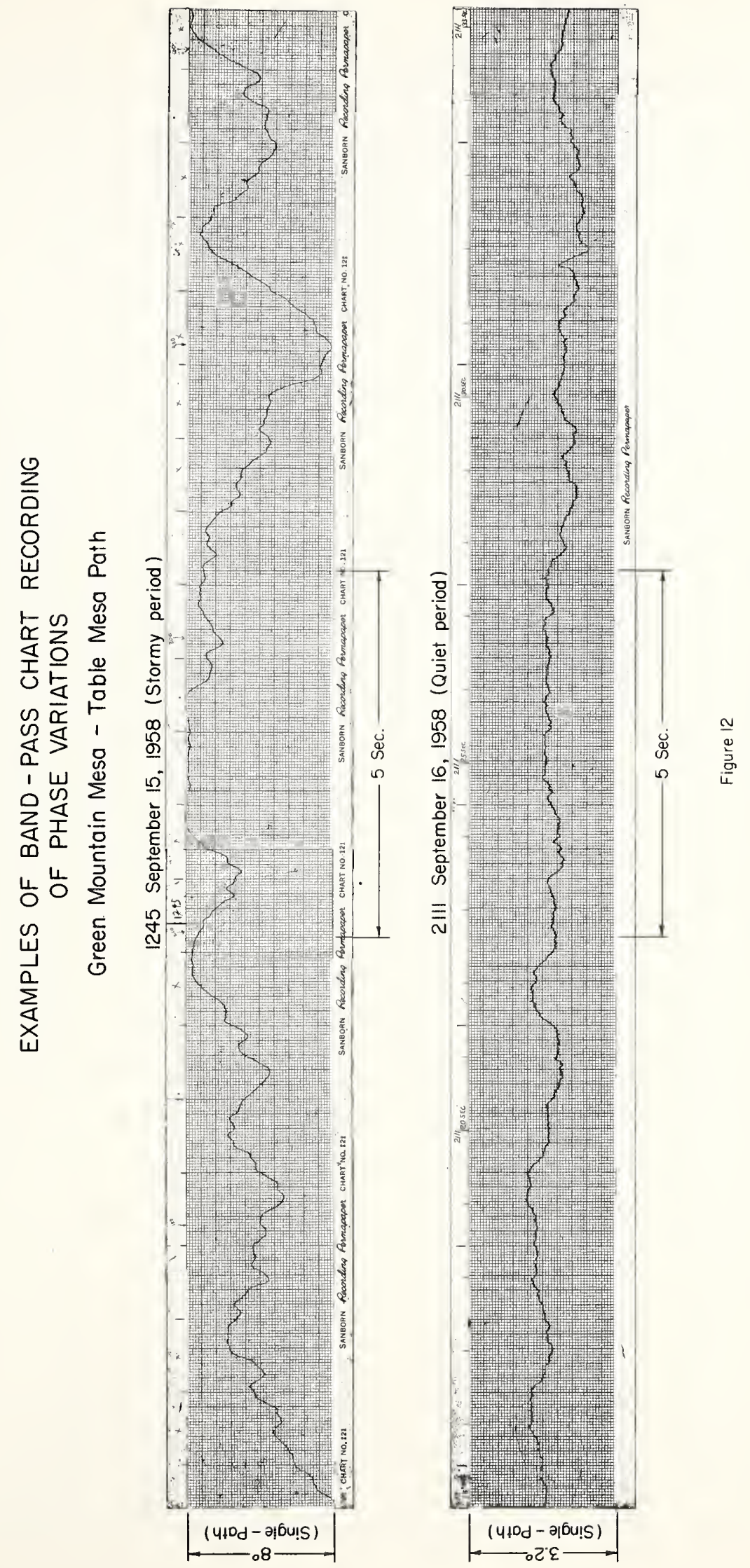
The output of the second recording circuit consisted of a Sanborn chart having full-scale ranges of 1.6 to 8 single-path degrees and moving at the rate of 25 millimeters per second. Two examples of this record are shown in Fig. 12. Its frequency response characteristic, shown in Fig. 13, consisted of a pass-band extending from about 0.03 cycles per second to about 30 cycles per second. This circuit was operated for 21 periods (see Table II), each about five minutes in length, distributed over the 40-hour period. Records from the other recording channels were not used in the analysis.

Seven of the 21 Sanborn recording periods were chosen for the power spectrum analysis, the only criterion used in their selection being that they should be fairly evenly spaced over the forty hour period. The analysis of each period consisted of first computing the spectrum in the range 0.83 to 12.5 cycles per second for two adjacent data segments each 0.5 minute in length, using a sampling interval of 0.04 second. Then the two segments were combined, the sampling interval increased to 0.2 second and the spectrum computed for the range 0.083 to 2.5 cycles per second. This yielded 14 sample spectra in the higher frequency range and 7 in the lower range of the Sanborn records.

From consideration of the frequency response of the recording circuit and from visual inspection of the records, it is felt that the 7 lower range spectra are not seriously contaminated by frequencies below 0.083 cycle per second. However, the possibility of such contamination is greater in the 14 higher range spectra, so the latter data were subjected to a digital trend removal process. (In all cases, the

This process consists simply of computing the deviations of the variable from a running average, computing the power spectrum of these deviations and correcting the result for the frequency response of this high-pass "filter." This, in effect, filters out variations at spectral frequencies below a cutoff frequency which is determined by the averaging time. 
spectra were corrected to allow for the recording circuit response.)

The analysis of the Varian low-pass data consisted of first digitizing the entire 40-hour run with a sampling interval of 0.5 minute. Then five sample spectra were computed, each using 6 to 8 hours of data, covering the range from 0.00111 to 0.0167 cycle per second. (1/15 to 1 cycle per minute.) Then two sample spectra were computed, each using 15 hours of data and covering the range from 0.000278 to 0.00417 cycle per second ( $1 / 60$ to $1 / 4$ cycle per minute), and finally, one spectrum utilizing all 40 hours of data and covering the frequencies from 0.0000926 to 0.00139 cycle per second ( 8 cycles per day to $1 / 12$ cycle per minute). In each case, the data were subjected to the trend removal process to minimize the effects of variations at frequencies below the range covered in the computation.

Table III lists miscellaneous information about each of the sample spectra. The individual spectral densities for each sample are plotted in Fig. 14. The points shown in red were computed from data recorded during the stormy afternoon of September 15. As can be seen in Fig. 10, the phase recording during that period was characterized by rapid fluctuations which did not recur during the remainder of the experiment. The corresponding spectra were sufficiently different from all the subsequent ones to warrant distinguishing them from the rest. The solid lines join the medians of the sample spectral densities for each group of spectra, excluding those shown in red. The range of the points at any given frequency is determined both by sampling fluctuations and by more or less long-term changes in propagation conditions (non-stationarity). Some measure of the relative magnitude of these two effects can be obtained by considering the distribution of spectral densities to be expected if the samples had been taken from the same statistical popu- 


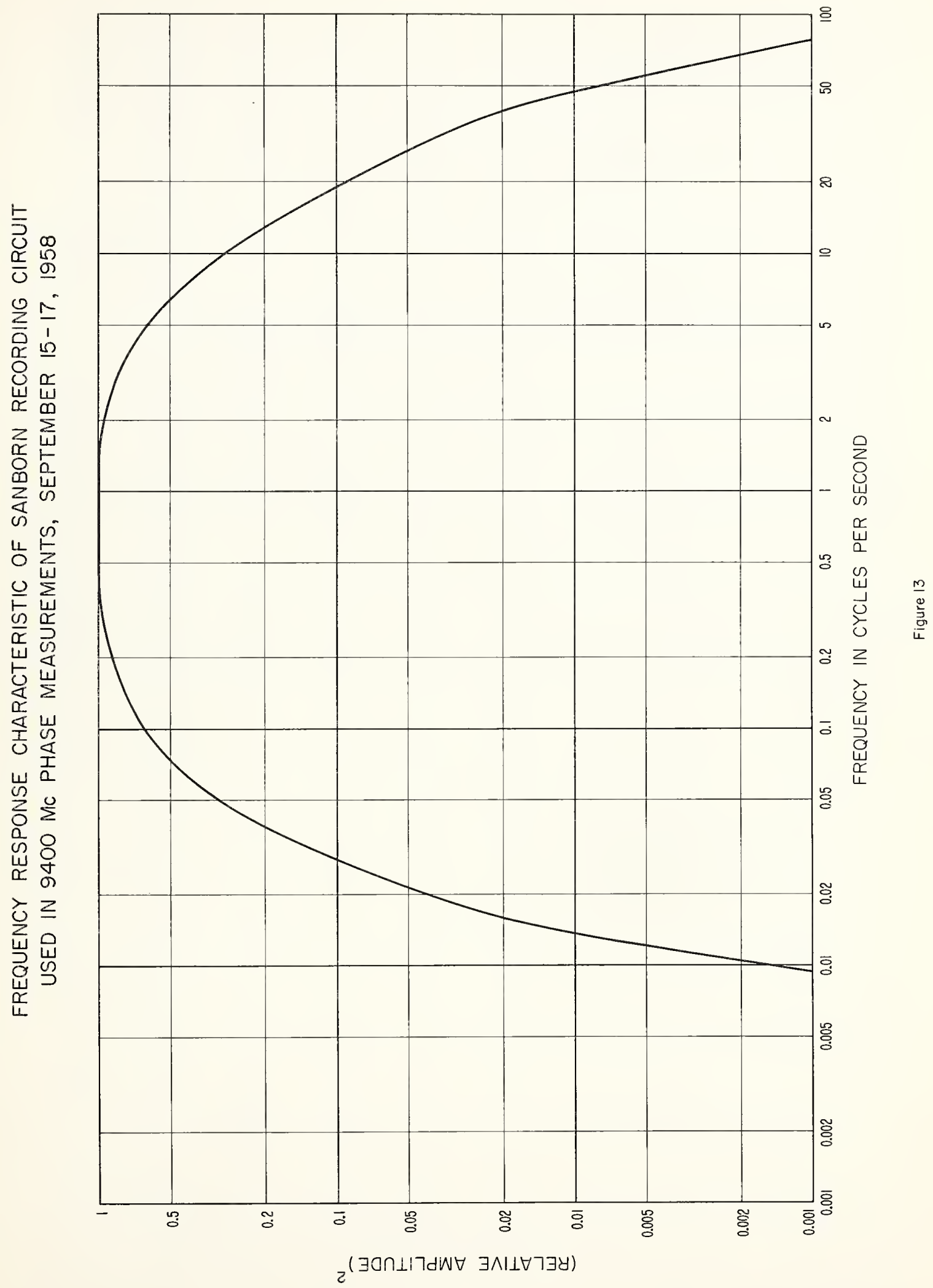





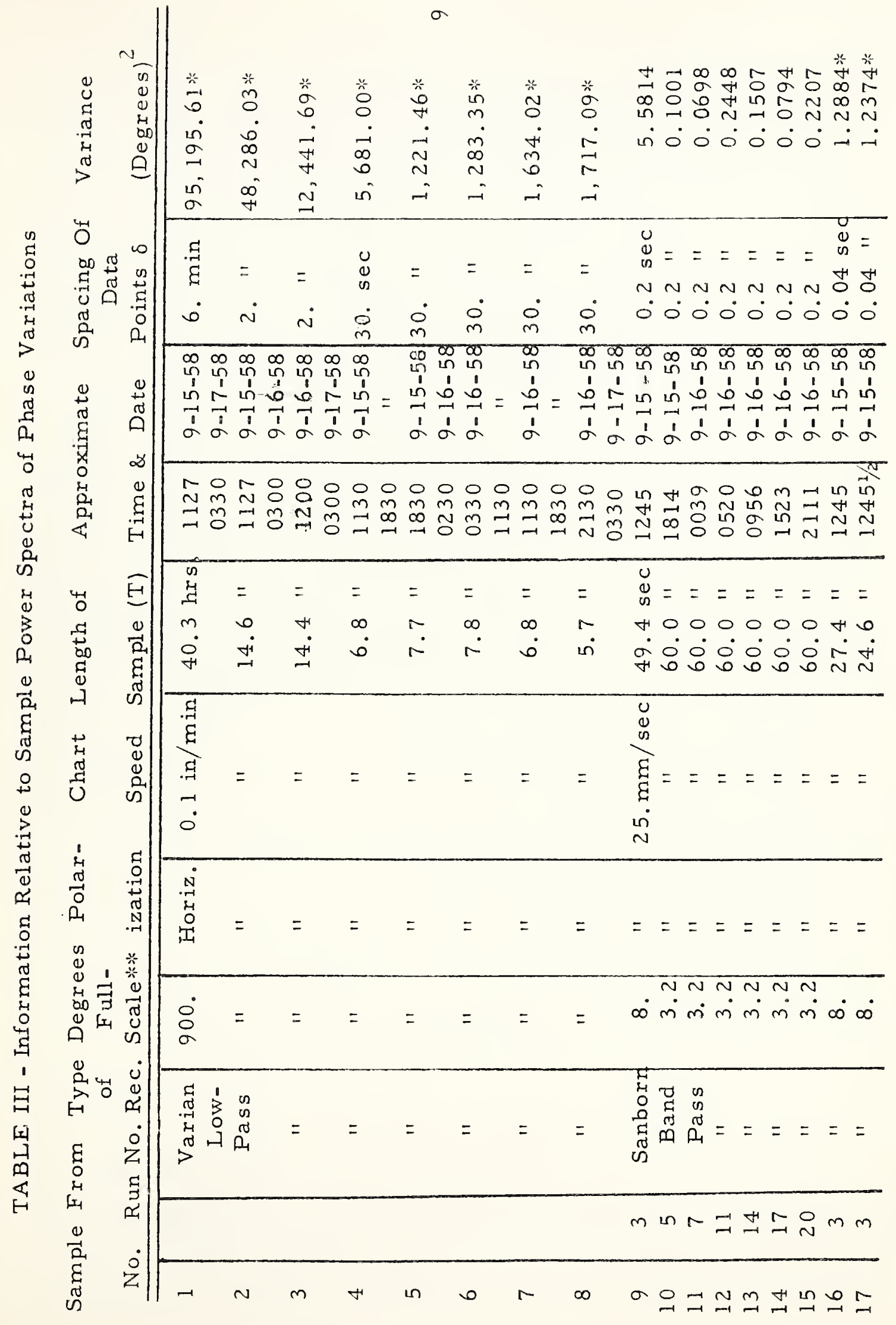





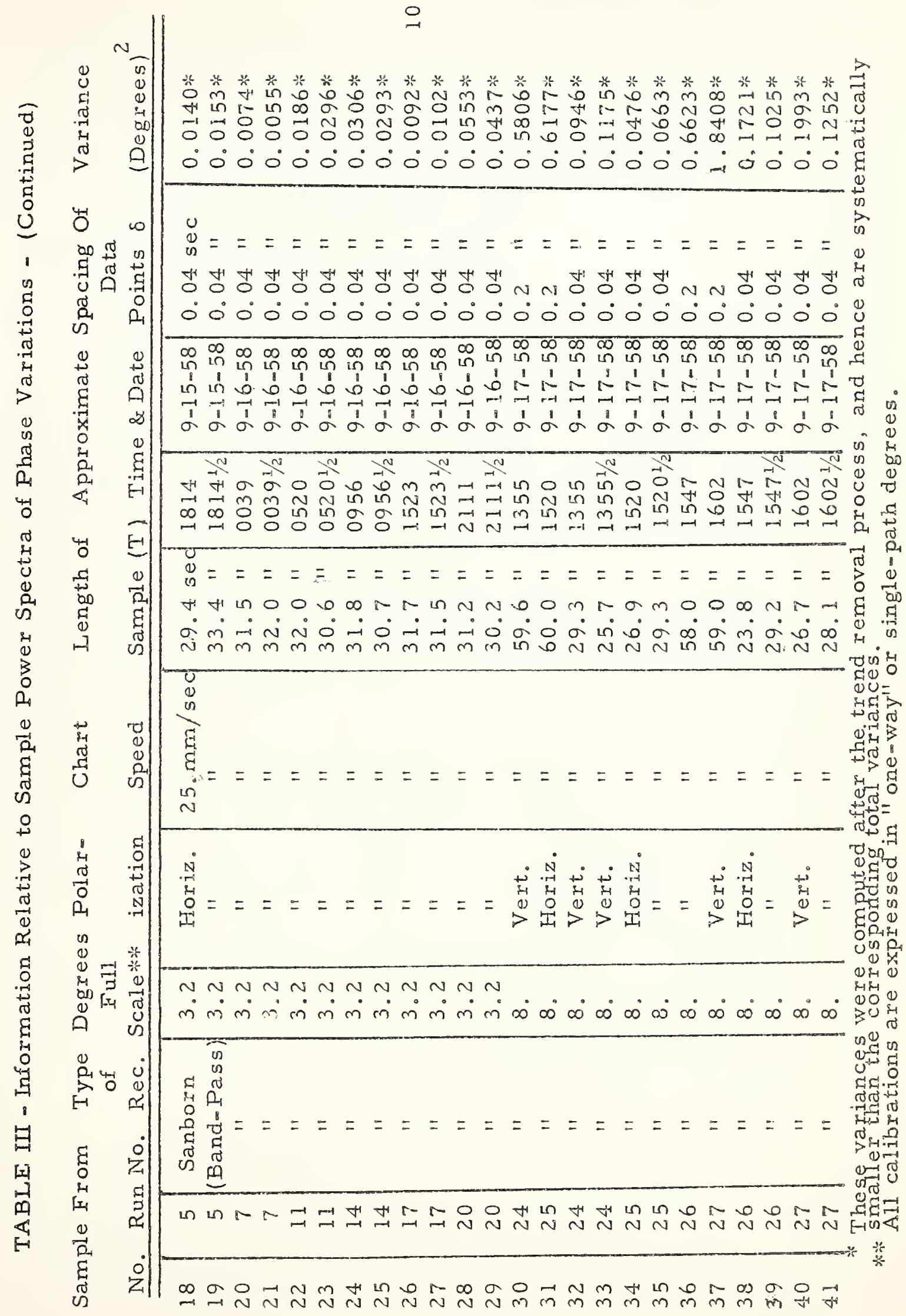





\section{POWER SPECTRUM OF PHASE VARIATIONS \\ IN 9400 MC TRANSMISSIONS OVER A 9.4-MILE PATH}

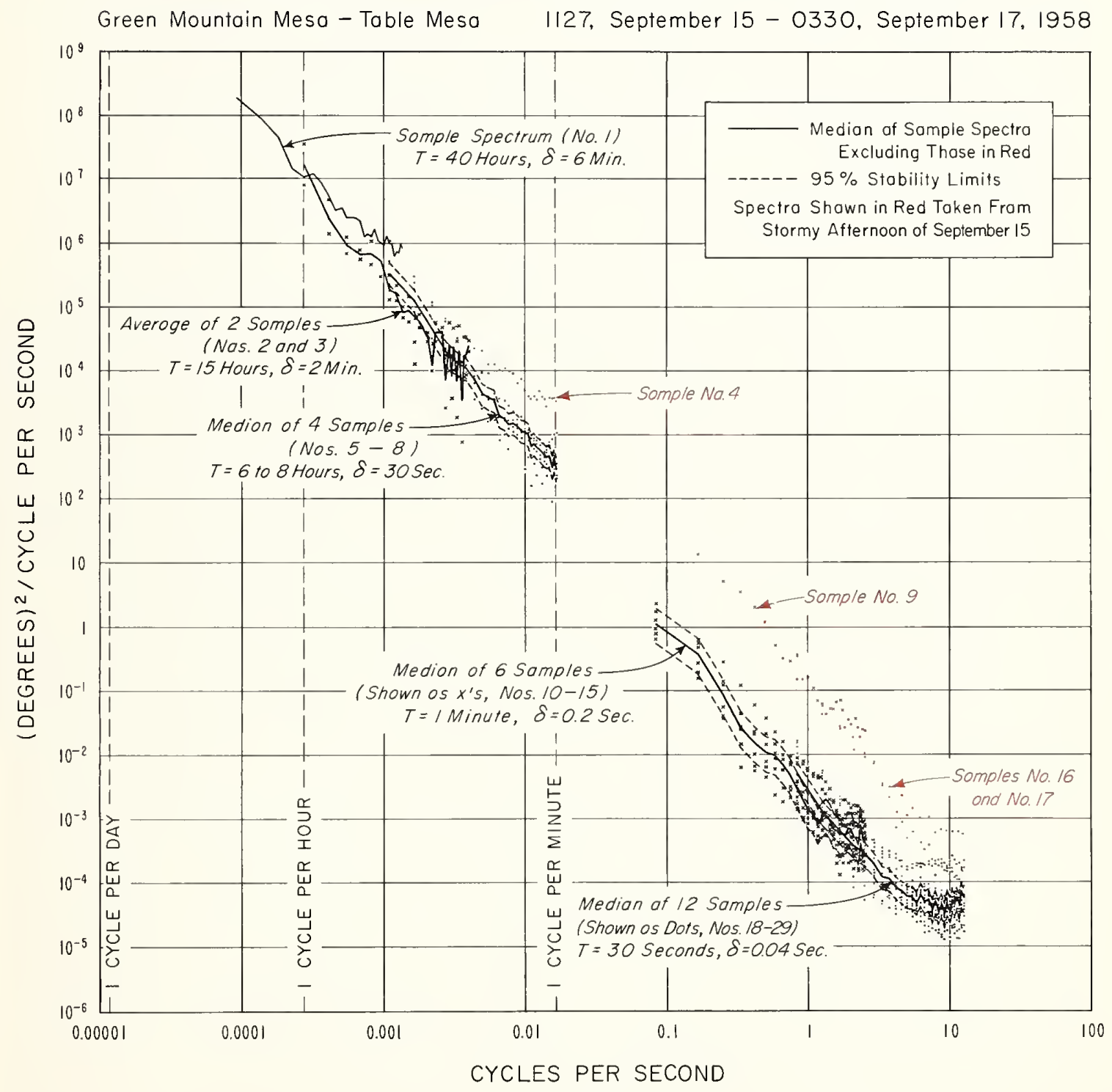

Figure 14 
lation, i.e., if the time variations in phase constituted a stationary process. In that case the spcctral density estimates at each frequency would be distributed according to the chr-squared distribution with an effective number of degrees of freedom determined by the number of data points used in each estimate, the number of frequencies for which estimates were computed, and, to a very limited extent, by the slope of the spectrum. Using the sample median to approximate the "true" median, the dashed lines labelled "95\% stability limits" represent the bounds within which $95 \%$ of all such spectral estimates might be expected to fall if the process were indeed stationary. In view of the large long-term changes in phase and meteorological conditions shown in Figs. 7 and 8 , it is not surprising that about $50 \%$ of the spectral estimates fall outside the $95 \%$ stability limits, indicating systematic changes in spectral density over the 40.n hour period. In fact, it is remarkable that the sample spectra are so similar, both in slope and magnitude.

It will be noted that there is a tendency for the slope to approach zero at the high frequency end of each set of spectra. This is caused by "aliasing," or the addition to the computed densities of power actuaily present at the higher frequencies. For spectra having steep slopes (such as these) aliasing causes an error which is about 2 to 1 at the highest frequency of each spectrum and which diminishes rapidly with frequency. Additional flattening of the spectrum above about 6 cycles per second is probably caused by "noise" introduced in the process of reading and analyzing the data, and should be ignored. Making allowances for aliasing and reading error noise, is appears that the slope of the phase spectrum is essentially constant over the range from 8 cycles per day to 12.5 cycles per second, the power density being approximately proportional to $\mathrm{f}^{-2.8}$. 
Figs. 15 and 16 show the seven spectra from the lower frequency range of the Sanborn data and the five spectra from the high frequency range of the Varian data identified individually by time of day. In general, there appears to be no outstanding correlation between these spectra and either the time of day or gross meteorological variations (with the obvious exception of the spectra taken from the stormy afternoon of September 15). One is tempted to attach some significance to the fact that the phase variance was somewhat lower during the period of high humidity following the storm than it was later during the period of warmer and drier weather. This is, of course, too small a data sample to warrant drawing any conclusions, and the correlation of phase and meteorological data will be thoroughly studied in subsequent measurements.

During the afternoon of September 17 (after the 40-hour run), the polarization of the antennas at both ends of the path was changed from horizontal to vertical and back again to horizontal. Samples of phase variations before and after the changes were analyzed to determine if the power spectrum is influenced by the choice of polarization. Figs. 17 and 18 show the results of this analysis. There is no indication that polarization has any effect on the phase data. This lends some support to the belief that there is little possibility of multi-path effects caused by ground reflections from the mesa at Roberts Lake (See Figs. 1 and 2). In summary, the phase spectrum analysis described here indicates that: (1) the slope of the power spectrum is nearly constant over the range of frequencies from $0.0001 \mathrm{cps}$ to about $10 . \mathrm{cps}$, the spectral densities being roughly proportional to $f^{-2.8} ;$ (2) except for the afternoon of September 15 when a rainstorm crossed the path and caused large high frequency fluctuations in phase, the power spectrum remained 
SAMPLE POWER SPECTRA OF PHASE VARIATIONS

IN 9400 MC TRANSMISSIONS OVER A 9.4 MILE PATH

Green Mt. Mesa-Table Mesa Low-Pass Varian Recording

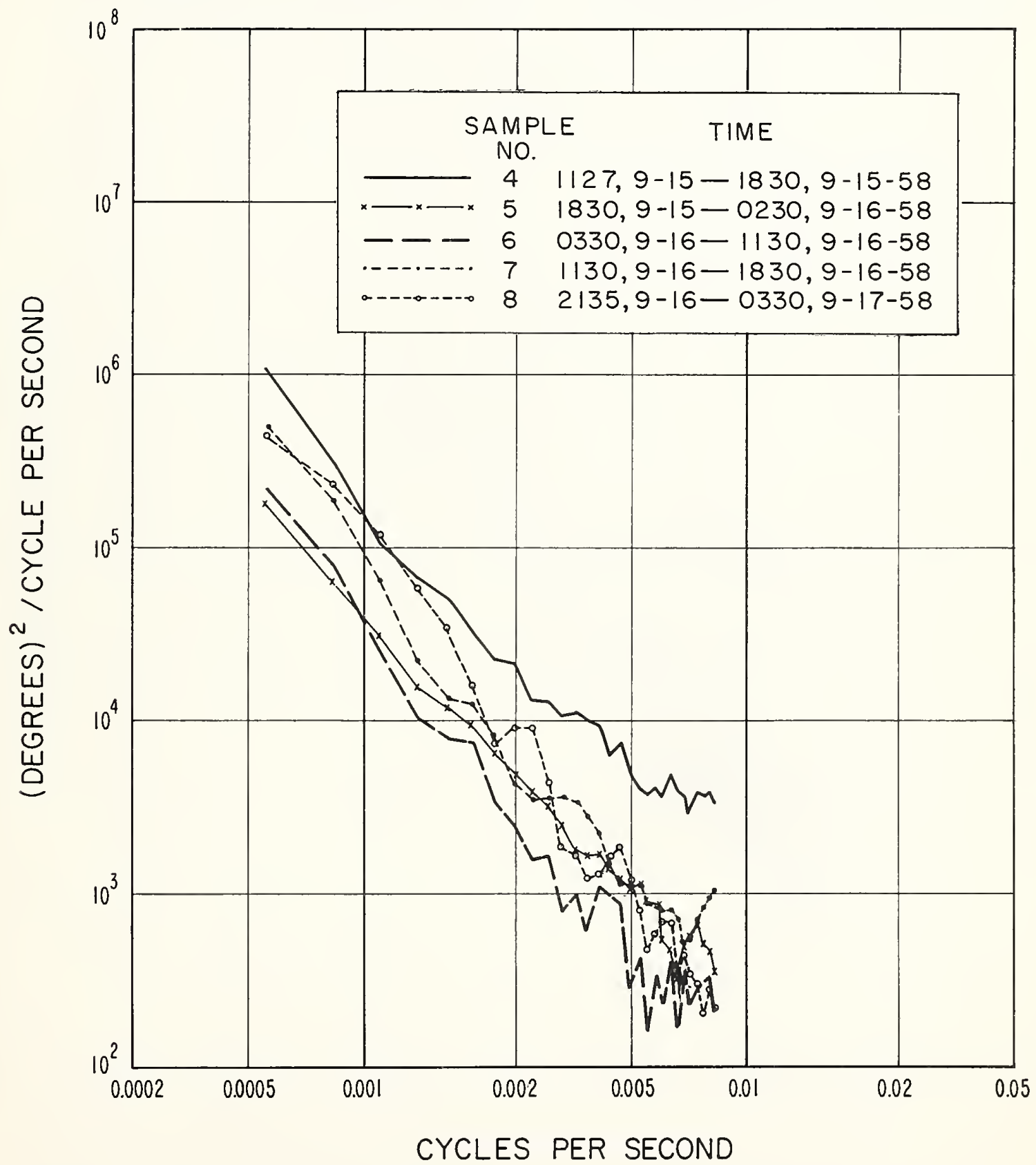

Figure 15 

SAMPLE POWER SPECTRA OF PHASE VARIATIONS IN $9400 M C$ TRANSMISSIONS OVER A 9.4-MILE PATH

Green Mountain Mesa-Table Mesa

Band-Pass Sanborn Recording

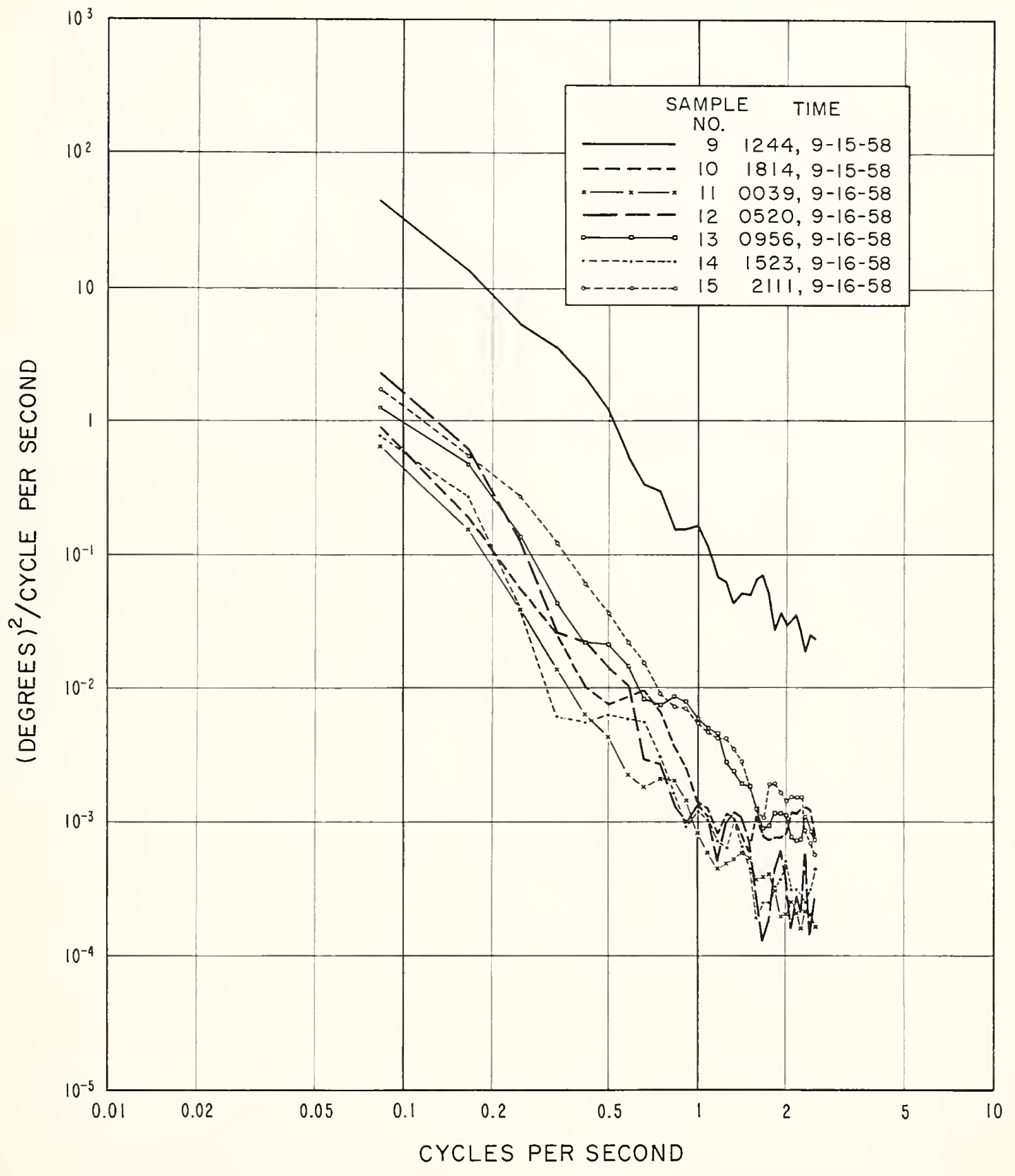

Figure 16 

COMPARISON OF POWER SPECTRA OF 9400 MC PHASE VARIATIONS USING HORIZONTAL AND VERTICAL POLARIZATION

Green Mountain Mesa-Table Mesa Path

September 17,1958

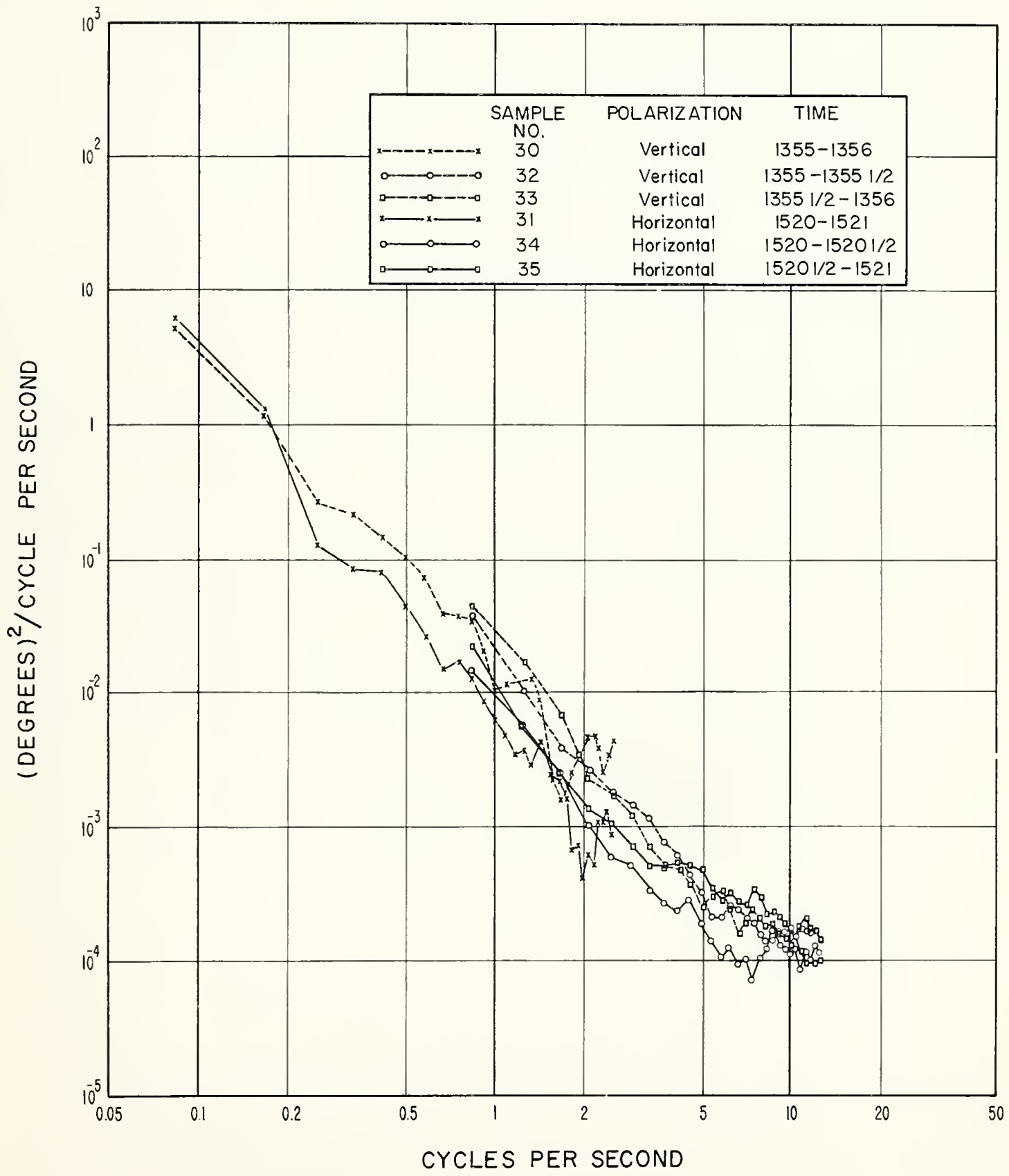

Figure 17 

COMPARISON OF POWER SPECTRA OF 9400 MC PHASE VARIATIONS USING HORIZONTAL AND VERTICAL POLARIZATION

Green Mountain Mesa - Table Mesa Path

September 17, 1958

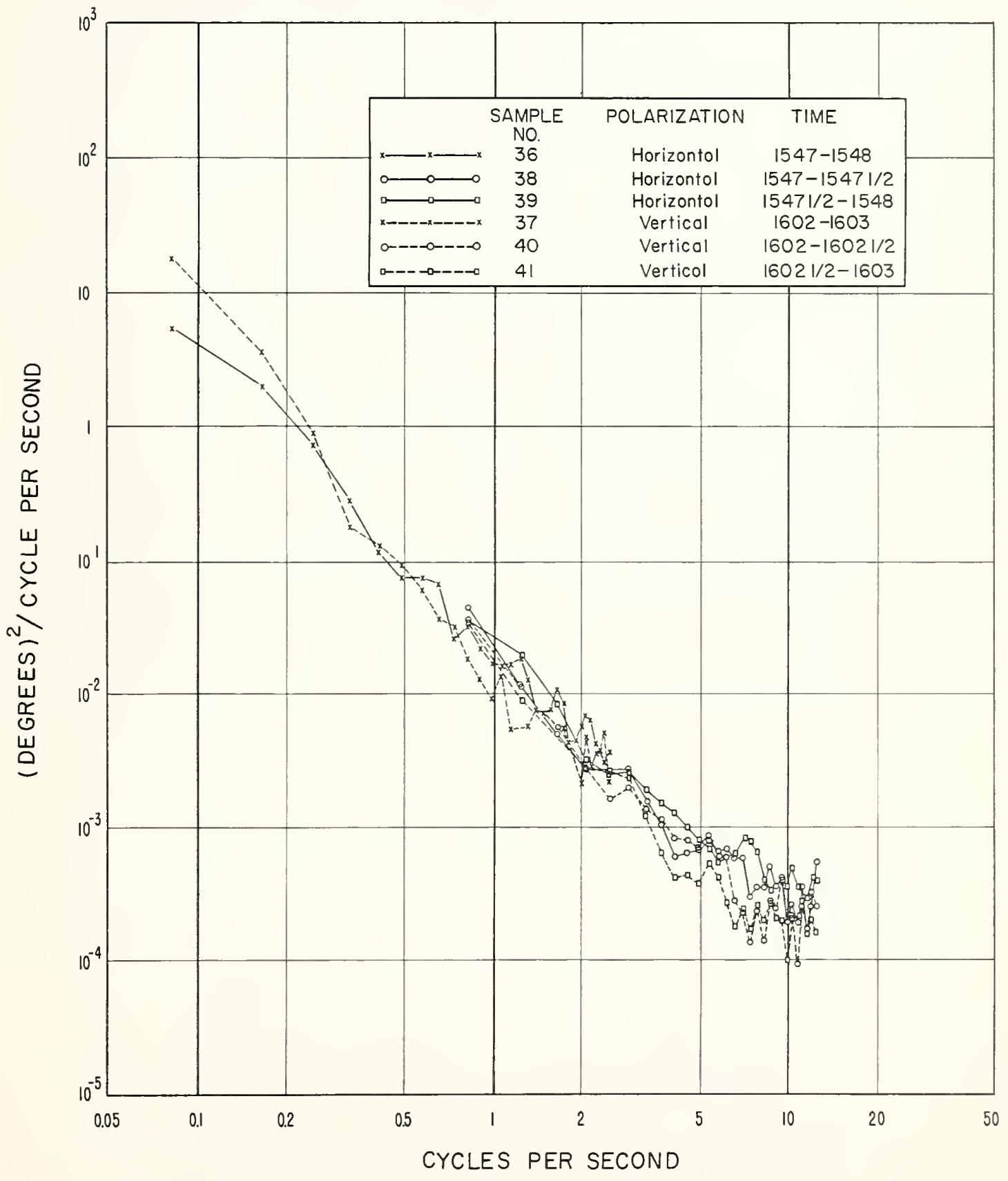

Figure 18 

fairly constant as a function of time both with regard to magnitude and to slope; (3) the phase variations appear to be insensitive to changes in polarization.

The time vaxiations in phase can also be intexpreted as variations in the radio frequency of the received signal. (See appendix). The frequency variation spectrum can be obtained from the phase spectrum simply by multiplying the latter by the square of the spectral frequency (with appropriate conversion of units.)

Fig. 19 shows the frequency variation spectra corresponding to the phase spectra shown in Fig. 13. They were obtained by multiplying the phase spectral density at the frequency $f$ cycles per second by $\left(\frac{\pi f}{180}\right)^{2}$. The spectral density of radio frequency variations decreases relatively slowly with increasing spectral frequency, being approximately proportional to $\mathrm{f}^{-0.8}$. (The exponent here is simply the value obtained for the phase spectrum increased by 2.) The apparent increase in power at the high frequency end (above about 6 cycles per second) is caused by the reading error noise mentioned previously and should be ignored.

\section{FUTURE, PLANS}

In conference with representatives from Space Technology Laboratories, held in Boulder on 9-25-56, the following plans were agreed upon for the next phase of activities.

1. The effects of antenna size will be investigated by repeating the $\mathrm{x}$-band measurements over the 9.4 mile path using 4 foot parabolic antemnas and attempting to extend the run to 5 days without interruption. The majority of the data will be taken using horizontal polarization with some samples 
of vertical included. The primary recordings of variations in phase of the radio signals will be supplemented by surface measurements of temperature pressure, relative humidity, and velocity. Microwave refractometers and time-lapse movies will be added as the equipment becomes available to provide a more complete picture of the local atmospheric conditions.

2. The experiments described in 1 will be repeated over a 2 mile path using the 18 inch antennas and over the 9.4 mile path using $1000 \mathrm{MC}$ and 10 foot parabolic antennas.

3. An additional series of experiments will be performed using 18 inch antennas, $9400 \mathrm{MC}$, and a path of a few thousand feet with two antennas at one terminal. These will be arranged so that one is near a maximum in the height-gain pattern and the other is near a minimum. The phase variations of each of the two paths will be measured independently but simultaneously in an attempt to determine the effects of ground-reflection on the phase stability.

\section{ACKNOW LE.DGEMENTS}

The following personnel were responsible for the work reported above: J. T. Collins, F. E. Freethey, W. B. Grant, D. P. Harris, H. B. Janes, A. W. Kirkpatrick, D. Smith, M. J. Vetter and D. M. Waters. Project leader was Moody C. Thompson, Jr.

The assistance of J. W. Herbstreit and K. O. Hornberg is also gratefully acknowledged. 


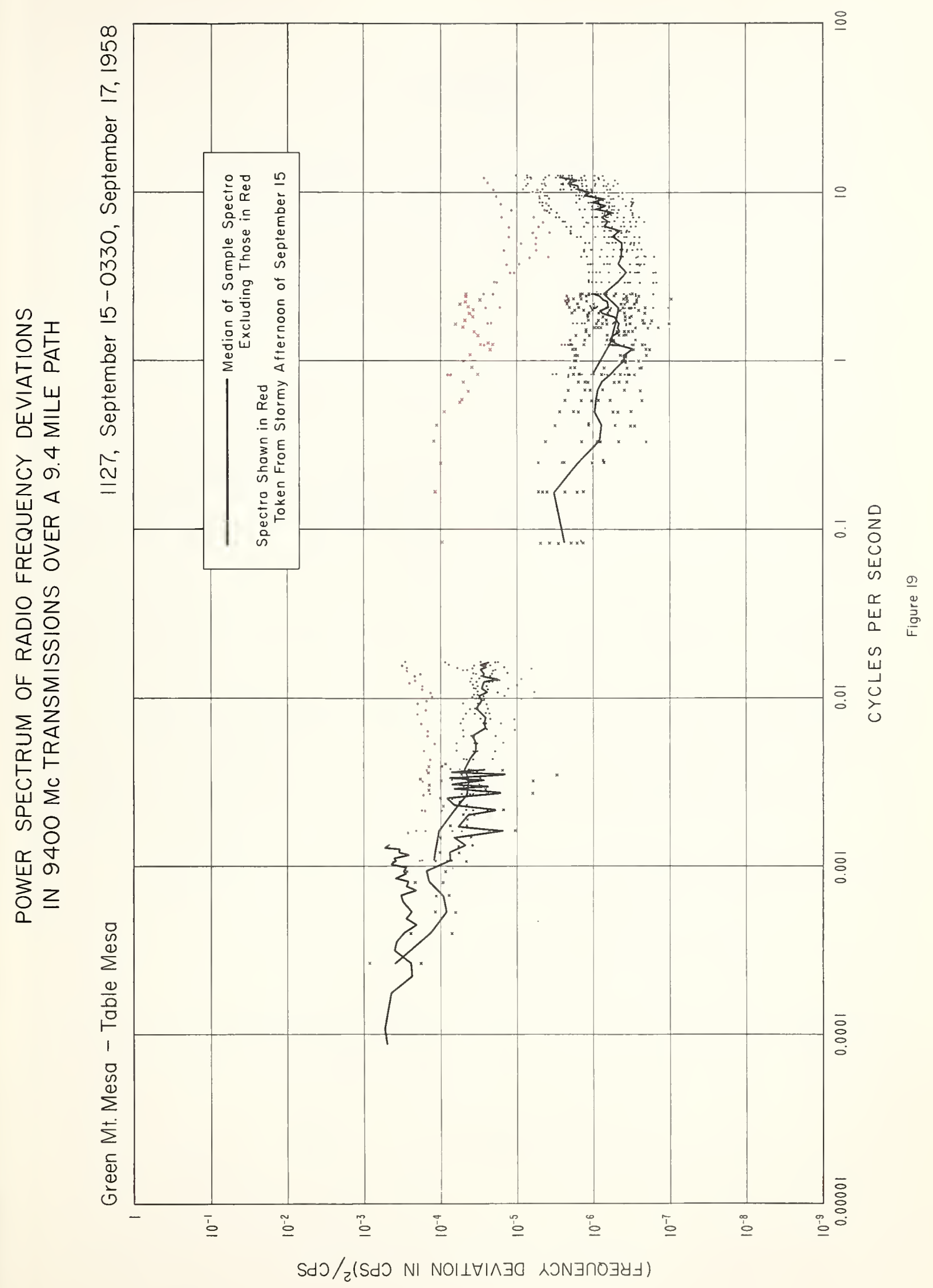





\section{APPENDIX}

To express the effects of the atmospheric turbulence on the propagated signal in terms of its frequency-modulation effects rather than phase variations, we may write the transmitted and received waves (ignoring attenuation) as follows:

$$
\begin{aligned}
& e_{T}=\epsilon^{i \omega t} \\
& e_{R}=\epsilon^{i(\omega t-k 1)}=\epsilon^{i(\omega t-\theta)}
\end{aligned}
$$

If we define the frequency of the received signal as the time derivative of the total phase term we obtain:

$$
\begin{aligned}
& \omega^{\prime}=\omega-\frac{\partial \theta}{\partial t} \\
& \Delta \omega=\omega-\omega^{\prime}=\frac{\partial \theta}{\partial t}
\end{aligned}
$$

Thus, the frequency deviation from the turbulence is proportional to the slope of the phase records obtained in the experiment. To obtain the spectrum of the frequency deviation from the phase records is relatively simple.

If $\theta$ is some function of time which we assume can be represented as a Fourier series, we write:

$$
\theta(t)=\ldots+a_{n} \cos 2 \pi f_{n} t+\ldots
$$

and express its spectrum in terms of the values of $a_{n}$ corresponding to $f_{n}$. If we take the derivative of $\underline{5}$, we obtain a second series of the form:

$$
\frac{\partial \theta}{\partial t}=\ldots+2 \pi f_{n} a_{n} \sin 2 \pi f t+\ldots
$$


This may be expressed in the same form as $(5$

$$
\frac{\partial \theta}{\partial t}=\ldots+b_{n} \cos 2 \pi f_{n} t+\ldots
$$

in which each $b_{n}$ is related to the original coefficient $a_{n}$ by the equation

$$
b_{n}=2 \pi f_{n} a_{n}
$$

Consequently, the power spectra for frequency deviation may be obtained from the power spectra of phase of arrival by weighting each coefficient with the appropriate value of $\left(2 \pi f{ }_{n}\right)^{2}$. This is done very simply in the IBM 650 programming and each ordinate in the frequency deviation spectra is obtained from the corresponding ordinate in the phase spectrum by this process. 


\section{RE.FERENCES}

1. M. C. Thompson, Jr. and M. J. Vetter, "Single Path Phase Measuring System For Three-Centimeter Radio Waves," Review of Scientific Instruments, December, 1959.

2. R. B. Blackman and J.W. Tukey, "The Measurement of Power Spectra From the Point of View of Communication Engineering," Parts I and II, The Bell System Technical Journal, Vol. XXXVII, No. 1, pp. 185-280, January 1958, and No. 2, pp. 485 - 569, March 1958. 

U. S. DEPARTMENT OF COMMERCE

Sinclair Weeks, Secretary

NATIONAL BUREAU OF STANDARDS

A. V. Astin, Director

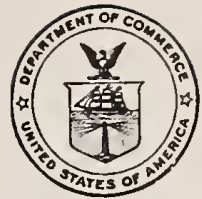

\section{THE NATIONAL BUREAU OF STANDARDS}

The scope of the scientific program of the National Bureau of Standards at laboratory centers in Washington, D. C., and Boulder, Colorado, is given in the following outline: Washington, D.C.

Electricity and Electronics. Resistance and Reactance. Electron Devices. Electrical Instruments. Magnetic Measurements. Dielectrics. Engineering Electronics. Electronic Instrumentation. Electrochemistry.

Optics and Metrology. Photometry and Colorimetry. Optical Instruments. Photographic Technology. Length. Engineering Metrology.

Heat. Temperature Physics. Thermodynamics. Cryogenic Physics. Rheology. Engine Fuels. Free Radicals.

Atomic and Radiation Physics. Spectroscopy. Radiometry. Mass Spectrometry. Solid State Physics. Electron Physics. Atomic Physics. Neutron Physics. Nuclear Physics. Radioactivity. X-rays. Betatron. Nucleonic Instrumentation. Radiological Equipment. AEC Radiation Instruments.

Chemistry. Organic Coatings. Surface Chemistry. Organic Chemistry. Analytical Chemistry. Inorganic Chemistry. Electrodeposition. Molecular Structure and Properties. Physical Chemistry. Thermochemistry. Spectrochemistry. Pure Substances.

Mechanics. Sound. Mechanical Instruments. Fluid Mechanics. Engineering Mechanics. Mass and Scale. Capacity, Density, and Fluid Meters. Combustion Controls.

Organic and Fibrous Materials. Rubber. Textiles. Paper. Leather. Testing and Specifications. Polymer Structure. Plastics. Dental Research.

Metallurgy. Thermal Metallurgy. Chemical Metallurgy. Mechanical Metallurgy. Corrosion. Metal Physics.

Mineral Products. Engineering Ceramics. Glass. Refractories. Enameled Metals. Concreting Materials. Constitution and Microstructure.

Building Technology. Structural Engineering. Fire Protection. Air Conditioning, Heating, and Refrigeration. Floor, Roof, and Wall Coverings. Codes and Safety Standards. Heat Transfer. Applied Mathematics. Numerical Analysis. Computation. Statistical Engineering. Mathematical Physics.

Data Processing Systems. SEAC Engineering Group. Components and Techniques. Digital Circuitry. Digital Systems. Analogue Systems. Application Engineering.

- Office of Basic Instrumentation

- Office of Weights and Measures

Boulder, Colorado

BOULDER LABORATORIES

F. W. Brown, Director

Cryogenic Engineering. Cryogenic Equipment. Cryogenic Processes. Properties of Materials. Gas Liquefaction.

Radio Propagation Physics. Upper Atmosphere Research. Ionosphere Research. Regular Propagation Services. Sun-Earth Relationships. VHF Research. Ionospheric Communications Systems.

Radio Propagation Engineering. Data Reduction Instrumentation. Modulation Systems. Navigation Systems., Radio Noise. Tropospheric Measurements. Tropospheric Analysis. Radio Systems Application Engineering.

Radio Standards. High Frequency Electrical Standards. Radio Broadcast Service. High Frequency Impedance Standards. Electronic Calibration Center. Microwave Physics. Microwave Circuit Standards. 


$$
\begin{aligned}
& \text { 至 }
\end{aligned}
$$

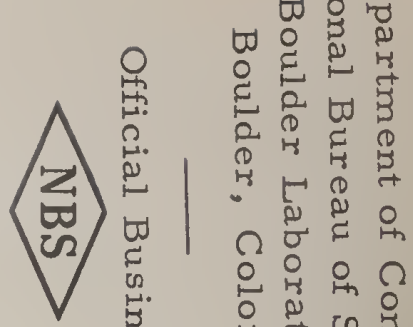

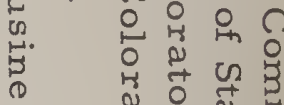

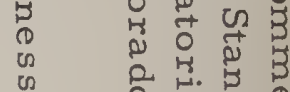

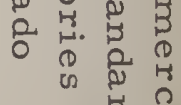

$$
\begin{aligned}
& \begin{array}{ll}
\text { an } & \text { की } \\
0 & 0 .
\end{array}
\end{aligned}
$$

- t

$\nabla 0$

का

H

उั

52

त

品

$\Omega$ in

○ 1

范

ก 